\title{
Article \\ Personalized Augmented Reality Based Tourism System: Big Data and User Demographic Contexts
}

\author{
Soheil Rezaee ${ }^{1,+}$, Abolghasem Sadeghi-Niaraki ${ }^{1,2, *,+}$, , Maryam Shakeri ${ }^{1}$ and Soo-Mi Choi ${ }^{2} \mathbb{C}$ \\ 1 Geoinformation Technology Center of Excellence, Faculty of Geodesy and Geomatics Engineering, K.N. Toosi \\ University of Technology, Tehran 19697, Iran; soheilrezaee@email.kntu.ac.ir (S.R.); \\ mshakeri@mail.kntu.ac.ir (M.S.) \\ 2 Deptartment of Computer Science and Engineering and Convergence Engineering for Intelligent Drone, \\ Sejong University, Seoul 143-747, Korea; smchoi@sejong.ac.kr \\ * Correspondence: a.sadeqi313@gmail.com \\ + These authors contributed equally to this work.
}

Citation: Rezaee, $\mathrm{S}$

Sadeghi-Niaraki, A.; Shakeri, M.; Choi, S.-M. Personalized Augmented Reality Based Tourism System: Big Data and User Demographic Contexts. Appl. Sci. 2021, 11, 6047. https://doi.org/10.3390/app11136047

Academic Editors: Chang-Hun Kim and Soo Kyun Kim

Received: 31 May 2021

Accepted: 22 June 2021

Published: 29 June 2021

Publisher's Note: MDPI stays neutral with regard to jurisdictional claims in published maps and institutional affiliations.

Copyright: (c) 2021 by the authors. Licensee MDPI, Basel, Switzerland. This article is an open access article distributed under the terms and conditions of the Creative Commons Attribution (CC BY) license (https:/ / creativecommons.org/licenses/by/ $4.0 /)$.

\begin{abstract}
A lack of required data resources is one of the challenges of accepting the Augmented Reality (AR) to provide the right services to the users, whereas the amount of spatial information produced by people is increasing daily. This research aims to design a personalized AR that is based on a tourist system that retrieves the big data according to the users' demographic contexts in order to enrich the AR data source in tourism. This research is conducted in two main steps. First, the type of the tourist attraction where the users interest is predicted according to the user demographic contexts, which include age, gender, and education level, by using a machine learning method. Second, the correct data for the user are extracted from the big data by considering time, distance, popularity, and the neighborhood of the tourist places, by using the VIKOR and SWAR decision making methods. By about $6 \%$, the results show better performance of the decision tree by predicting the type of tourist attraction, when compared to the SVM method. In addition, the results of the user study of the system show the overall satisfaction of the participants in terms of the ease-of-use, which is about $55 \%$, and in terms of the systems usefulness, about $56 \%$.
\end{abstract}

Keywords: augmented reality; big data; tourism; decision tree; VIKOR; SWARA

\section{Introduction}

Augmented Reality (AR) technology creates a significant potential to address the participatory issues in a simple and enjoyable way by creating smart and user-friendly applications, because it is estimated that $80 \%$ of human emotions are perceived by the eyes [1]. Today, the use of AR is expanding in many fields, and most of them represent only information that is stored on the central systems or on smart devices, which do not consider a large part of the information that is generated by the users [2]. In this case, the development of the AR applications will be limited, and the opportunities obtained through the information produced by the users will be lost, which has caused a shortage of data that involves the AR technology. However, the development of technology and new methods, the spread of Web 2.0 technologies, and social networks show that the spatial information produced by the users is valuable information that cannot be ignored. In this regard, sharing information in a simple and enjoyable way by the users is highly important [3].

The use of AR and social network technologies have been recently increasing in various fields, including tourism. Although there is a growing interest in developing a tourism system using AR technology and personalization methods, based on the authors' knowledge, there is no research that designed a personalized AR tourism system that considers the user demographic contexts as well as the spatial-temporal parameters in order to retrieve information from big data. In order to develop a personalized AR system, most of research was conducted to evaluate the potential of AR technology in the tourism 
field $[4,5]$, data modeling [2], and big data [6,7] integration, and personalizing the information visualization according to the user preferences $[8,9]$. With the personalization process of developed AR systems, the user preferences were extracted by either the user inputs or by mining the user history. Personalization by the user inputs $[8,9]$ and history have faced the problem for the new users, because there is no history, so it is difficult to insert preference for the users. There is no research that designed a personalized AR system that uses demographic information. On the other hand, the use of demographic contexts has been confirmed in order to improve the personalization process [10-13], especially for solving cold-start problems [14]. In addition, it was also evaluated in the tourism field by different studies $[10,15]$. However, they have not enabled the users to make decisions at any location and time by considering the spatial parameters and the decision-making methods.

The purpose of this research is to develop a personalized AR tourism system that is based on both the user demographics and the spatial-temporal contexts by using and analyzing big data produced by the users. In order to design this system, the machine learning and the decision-making methods are applied in order to predict the type of attractive place where the user is interested and to rank the attractive places. In the step of predicting the place type, the machine learning method is trained according to the demographic contexts, which include the user age, gender, and the education level. After the place is predicted, the places are ranked by considering time, distance, popularity, and the neighborhood of the tourist places. Finally, the system is evaluated in terms of the accuracy of the machine learning method by comparing the accuracy of the Decision Tree (DT) and the Support Vector Machine (SVM) methods, accuracy of the two algorithms, and the usability of the personalized AR based tourism system. Summarizing, the main novel contributions of the research follow:

- We develop a methodology to combine the demographic contexts and the spatialtemporal criteria using machine learning and decision-making methods in order to visualize the personalized information to the user through the AR technology.

- We develop a personalized AR tourism system that is based on the demographic and spatial-temporal contexts and to evaluate it through a user study.

The structure of this article follows. Section 2 explains the principles that are used in this study, which include the Step Wise Weight Assessment Ratio Analysis (SWARA) method and the VlseKriterijumska Optimizacija I Kompromisno Resenje (VIKOR) methods. In Section 3, the research methodology and the prediction and ranking are explained. Section 4 describes the data collection methods and the system development and implementation. Section 5 presents the evaluations and Section 6 contains the conclusion for this paper.

\section{Literature Review}

The number of studies that evaluated the AR potential is increasing in various fields, which include tourism [4-6,16-20], healthcare [21], and industry [22], so more attention has been given recently to developing personalized AR systems. The research related to the personalized AR tourist system is addressed in three parts in this section, which are the AR tourism systems, personalization based on demographic information, and big data in AR systems.

In the field of AR tourism systems, Han et al. [4] developed a tourism model for the AR tourism applications in the field of urban heritage tourism, which was developed for Dublin's historic cultural sites. Kim et al. [2] proposed a context-aware mobile AR system for a cultural heritage site in South Korea. This system was developed based on semantic web technology, which integrates five web databases interoperability. Tarantino et al. [8] designed an AR guide system, which is called GENnArí. It generated personalized multiday itineraries, so the number for attractiveness and PoIs were maximized, and the distance that the users travel was minimized. In this system, different constraints were considered in order to improve the quality of the recommendation, which included the opening and closing times of the POIs and the weather forecasts. Ji et al. [9] developed 
a personalized AR learning system for experiential learning of traditional handicraft, based on the learning preference of the user. Although they evaluated the personalized AR system in the learning domain, they did not apply user demographics in the personalization process. Choonsung Shin et al. [5] introduced a mobile augmented reality for cultural heritage places. They explained how to add the user-generated multimedia content to the AR.

There are several studies that focused on personalization in the recommendation systems [11,12,23-30]. Al-Shamri et al. [13] presented profiling the user in order to improve the demographic recommender systems by exploring the unified and isolated user profile approaches. Bahramian et al. [11] introduced a context-aware tourism advisory system that considered user feedback and the additional contextual information from the users, and they suggested a personalized tour for the users based on their preferences. Colomo-Palacios et al. [12] proposed a broad-based POST-VIA 360 platform that was conducted using an exploratory analysis method for the tourist advice, which included the location, time, and the activity information. Safoury et al. [14] and Wang et al. [15] evaluated the use of demographic information, which included age, gender, and occupation, in order to solve the cold-start problem. Zhao et al. [31] proposed a product recommender system that utilized the user demographic information, which included age, gender, and education. Garcia et al. [10] developed a personalized recommender system that generates a user model based on the user demographic attributes, and they recommend POIs using the hybrid content and collaborate filtering. Lee et al. [2] designed a tour system to dynamically schedule recommendations based on the user preferences and location. In some studies, the personalized systems were designed based on the user's mood [32,33]. Moscato et al. [32] evaluated a personalized music recommender system that recommends audio that is based on the user's personality and mood. By using NLP methods, the user's mood and personality were detected based on the user's behavior in social media. Amato et al. [33] designed a knowledge-based big data retrieval system for various applications related to art collections, which include recommender applications. The social data and social vision of cultural items, which include the general user' mood, were applied in the recommendation application. The user demographic information was not considered in these research studies.

In the field of using big data in AR systems, Balduini et al. [6] designed an augmented reality application called BOTTARI that was used to score a number of restaurants in Seoul, which is where an average of three million tweets are sent daily, and hundreds of thousands of them contained user comments about cafes, restaurants, and bars. This research was exclusively limited to one type of tourist place. Torres-Ruiz et al. [7] proposed a touristic recommender system that semantically recommended itineraries using social network data, which included Facebook, Foursquare, and Twitter. In this research, the typical questions were classified and the answers were displayed using a mobile AR application. The personalization process did not include the demographic information.

\section{Research Background}

\subsection{The SWARA Method}

The Step Wise Weight Assessment Ratio Analysis (SWARA) method was one of the newest methods used in 2010 by Cresolin et al. regarding the selection of a reasonable difference analysis method. This method is similar to the AHP [34] and ANP [35] methods, which are used to calculate the criteria weights in multicriteria decision-making problems. In this method, the experts first prioritize the criteria, and the most important criterion then takes the highest (top) priority. After that, the least important criterion receives the lowest rank. The main steps for the weighting according to the SWARA method are as listed below [36-40]:

Step 1: Sorting the indicators initially involves selecting the appropriate indicators that are indicated by the decision makers and arranging them as the final indicators based 
on their degree of importance. Accordingly, the most important indicators are in the higher categories, and the less important indicators are in the lower categories.

Step 2: Determining the relative importance of each indicator $\left(S_{j}\right)$ : During this stage, the relative importance of each indicator should be determined compared to the previous indicator, which involves determining the indicator that was more important in the SWARA method process. This value is indicated by $S_{j}$.

Step 3: Calculating the coefficient $K_{j}$ : The coefficient $K_{j}$, which is a function of the relative importance of each indicator, is calculated using Equation (1).

$$
K_{j}=S_{j}+1
$$

Step 4: Calculating the initial weight of each indicator: The initial weight of the indicators can be calculated by using Equation (2). In this regard, it should be noted that the weight of the first indicator, which is the most important, is considered to be equal to 1 .

$$
Q_{j}=\frac{q_{j}-\mathbf{1}}{k_{j}}
$$

Step 5: Calculating the final normal weight: In the last step of the SWARA method, the final weight of the indicators, which is also considered the normalized weight, is calculated by using Equation (3).

$$
W_{j}=\frac{q_{j}}{\sum q_{j}}
$$

\subsection{The VIKOR Method}

The Victor technique is used to optimize multicriteria problems in complex systems, and includes a multicriteria decision-making method for solving a discrete decision-making problem with disproportionate criteria, which involves different and conflicting units of measurement. The method was developed by Prokvik and Tzang. The main goal of the VIKOR technique is to be closer to the ideal answer of each index [13,15,41-46]. The steps from the VIKOR method are as listed below [13,15,42-44].

1. The Decision Matrix Formation: The decision matrix for the VIKOR method consists of an optional criteria matrix (Equation (4)). The criteria are placed in the column, and the research options we intend to rank are placed in the row. If the completion of the VIKOR decision matrix of criteria has a quantitative aspect, the real number is entered, but if it has a qualitative aspect, this process is done based on the range of 1 to 5 or 1 to 9 .

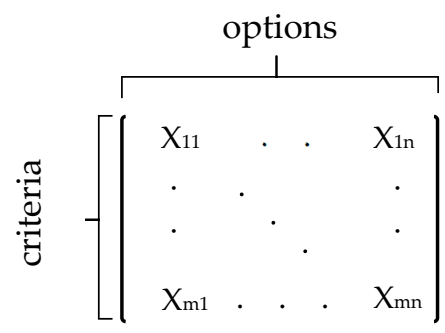

The Decision Matrix Normalization: The normalization process is conducted by using Equation (5). In order to normalize each value, we divide by the square root of the sum of the values of each standard column.

$$
W_{j} * \frac{X_{i}^{+}-X_{i j}}{X_{i}^{+}-X_{i}^{-}}
$$


2. The calculation the $S_{i}$ and $R_{i}$ values are computed from the previous step table, which is calculated using Equations (6) and (7).

$$
\begin{gathered}
S_{i}=\sum_{j=1}^{m} W_{j} * \frac{X_{i}^{+}-X_{i j}}{X_{i}^{+}-X_{i}^{-}} \\
\boldsymbol{R}_{i}=\max \left(W_{j} * \frac{X_{i}^{+}-X_{i j}}{X_{i}^{+}-X_{i}^{-}}\right)
\end{gathered}
$$

3. This step is related to the calculation of $S^{*}, S^{-}, R^{*}$, and $R^{-}$, which are obtained according to Equations (8)-(11).

$$
\begin{aligned}
S^{*} & =\operatorname{Min}\left(S_{i}\right) \\
S^{-} & =\operatorname{Max}\left(S_{i}\right) \\
R^{*} & =\operatorname{Min}\left(R_{i}\right) \\
R^{-} & =\operatorname{Max}\left(R_{i}\right)
\end{aligned}
$$

4. To obtain the VIKOR indicator $\left(Q_{i}\right)$, the $\mathrm{v}$ indicator is between 0 and 1 . It is called the weight of the maximum group strategy, which is generally considered to be 0.5 , is calculated using Equation (12).

$$
Q_{i}=v *\left[\frac{S_{i}-S^{*}}{S^{-}-S^{*}}\right]+(\mathbf{1}-v) *\left[\frac{\boldsymbol{R}_{i}-\boldsymbol{R}^{*}}{\boldsymbol{R}^{-}-\boldsymbol{R}^{*}}\right] .
$$

5. Options are ranked according to the value of the $Q_{i}$ calculated in the previous step. In this part, the lowest $Q_{i}$ value will be the first rank. The lower the $Q_{i}$ value, the better the ranking option will be.

6. The conditions $\mathrm{C} 1$ and $\mathrm{C} 2$ are checked:

Condition one: If the first option and the second option have the first rank and the second rank among $\mathrm{m}$ options, the relation below must be established, which is Condition 1.

$$
Q_{m}-Q_{l}<\frac{1}{1-j}
$$

The value of $j$ is the number of options that are considered.

Condition two: The first option must be recognized as the top rank in at least one of the $\mathrm{R}$ and $\mathrm{S}$ groups. If one of the conditions above is not met, then one of the conditions listed below will occur.

- Alternatives $\mathrm{A}(1)$ and $\mathrm{A}(2)$ if only condition 2 is not satisfied, or

- Alternatives $\mathrm{A}(1), \mathrm{A}(2), \ldots, \mathrm{A}(\mathrm{M})$ if condition 1 is not satisfied. $\mathrm{A}(\mathrm{M})$ is determined by the relation $Q\left(A_{m}\right)-Q\left(A_{1}\right)<\frac{1}{j-1}$ for maximum $\mathrm{M}$, and the positions of these alternatives are in closeness.

$$
Q\left(A_{m}\right)-Q\left(A_{1}\right)<\frac{1}{j-1}
$$

In this formula, the value of $j$ is the number of options available for ranking [47].

\section{Methodology}

The methodology used to design a personalized AR based system is shown in Figure 1. The methodology consists of place type prediction, place type filtering, ranking, and visualizations. These steps are explained in this section. 


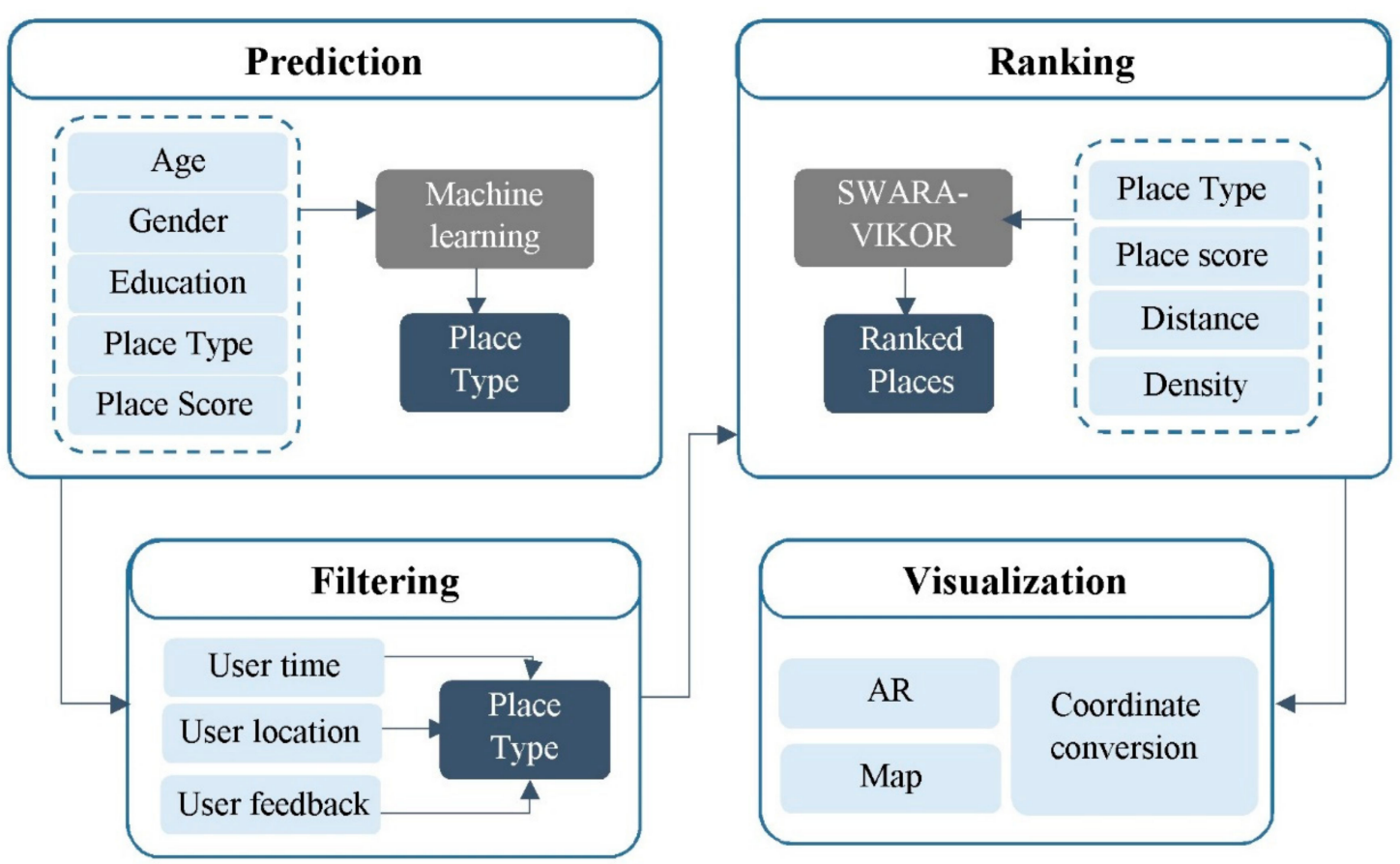

Figure 1. General implementation method.

\subsection{Place Type Prediction}

The first step of designing the personalized AR tourist system is to predict the type of tourist places where the user's interests are according to the user's demographic information. A machine learning method is used to do this in order to classify the tourist types by reflecting the user's interests. This method is conducted in order to achieve the associations between the place ranking and the demographic contexts. In the classification process, the place rate is considered in order to obtain what places the user is interested in visiting, which is based on the demographic contexts, in addition to the place type. For each user, the tourist places are classified into two classes, which include the favorite places and the unfavorite places, according to their ratings of the touristic places. After the normalizing the ranks of places between 0 and 10, if the rank of one place is less than 7 , it is considered as the unfavorite, otherwise it is the favorite place. Figure 2 shows the place type classification used in this research.

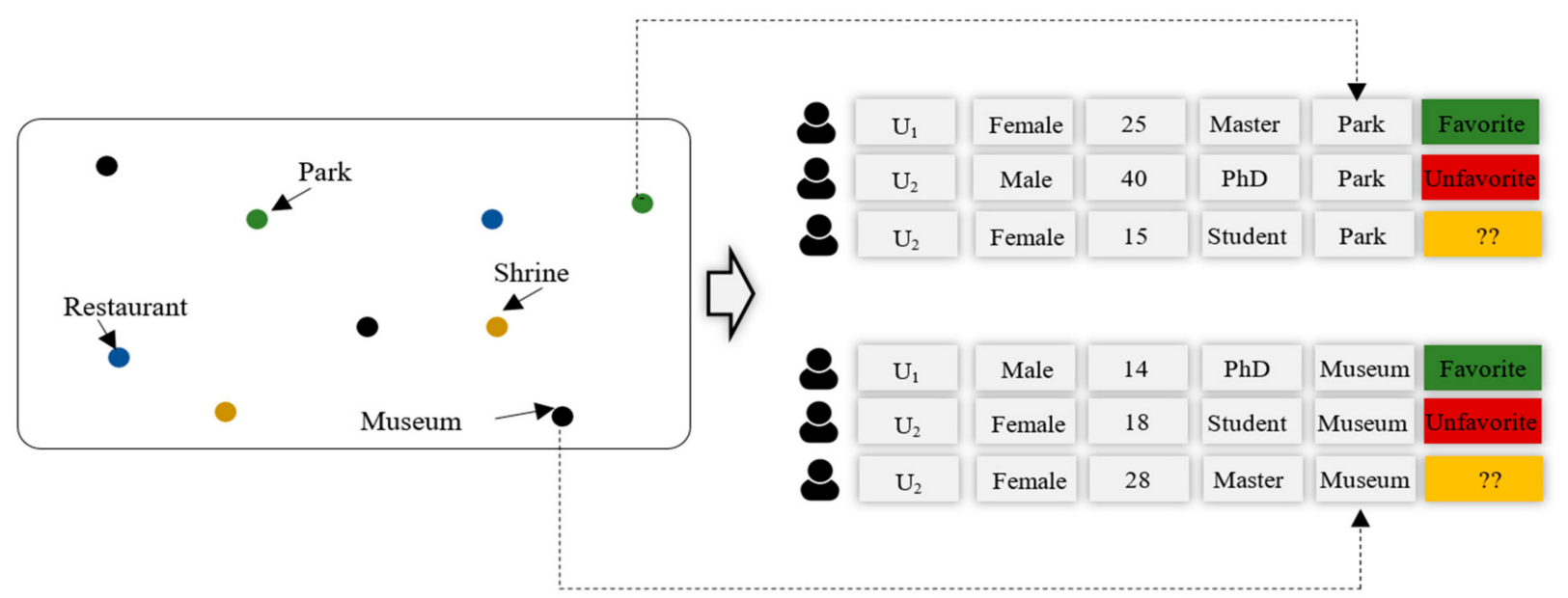

Figure 2. Place type classification according to the user's interests. 
In order to classify the tourist places to reflect the user's interests and preferences, the demographic context is considered, which includes gender, age, and level of education. It is clear that people who visit an attractive place often have similar interests and preferences. Studies [13,15,42-48] confirmed that the age and gender of a tourist is effective with tourism. These studies have also shown that the level of education of the individuals is important concerning the type of tourist activities they engage in. In order to visualize the most suitable places through an AR camera, we predicted the place types that the user is interested in by classifying similar users with similar demographic contexts.

The types of tourist places that a tourist may visit are shown in Figure 3 . In this figure, the tourist places are divided into eight main categories, which include residence, art and theater, entertainment and sports, restaurants and fast foods, green areas, natural attractions, religious attractions, and historical and cultural attractions. Each category contains several types of tourist places. For each place, two parameters are considered, which include the service time and service type, in addition to the spatial information. The service time is the length of time that the place is open and provides services to the users. The tourist places have different service times depending on their use. In addition, when a tourist is using tourism systems, they expect places that are out-of-service to have times that are not offered. Table 1 shows the service time of some tourist places in Tehran. Some places provide services to a specific gender, so the service type has one of these values: men services, women services, or none. For example, in Tehran, there are some places that provide services only to women, such as women's parks, swimming pools, and water parks.
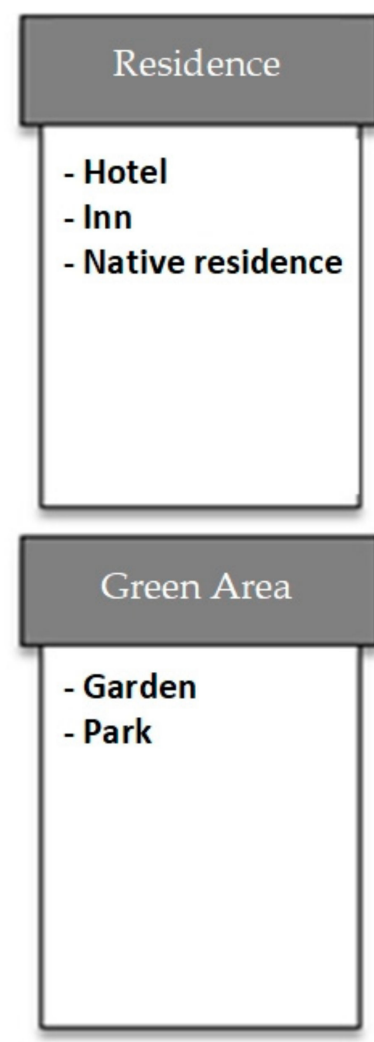
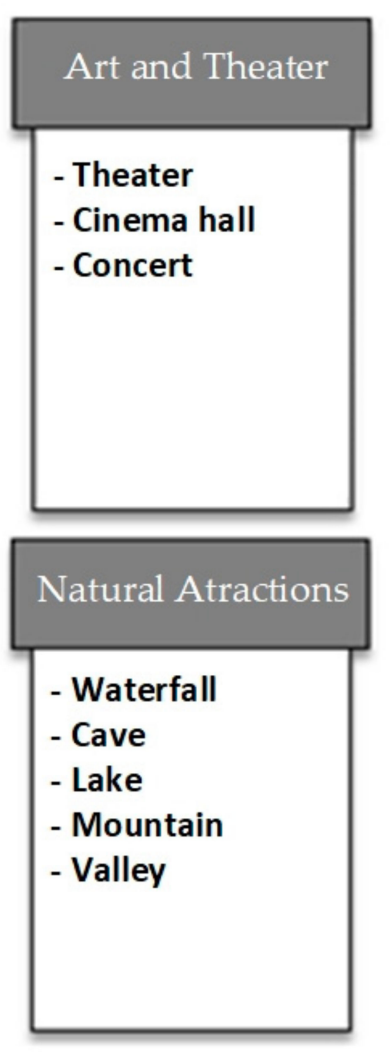
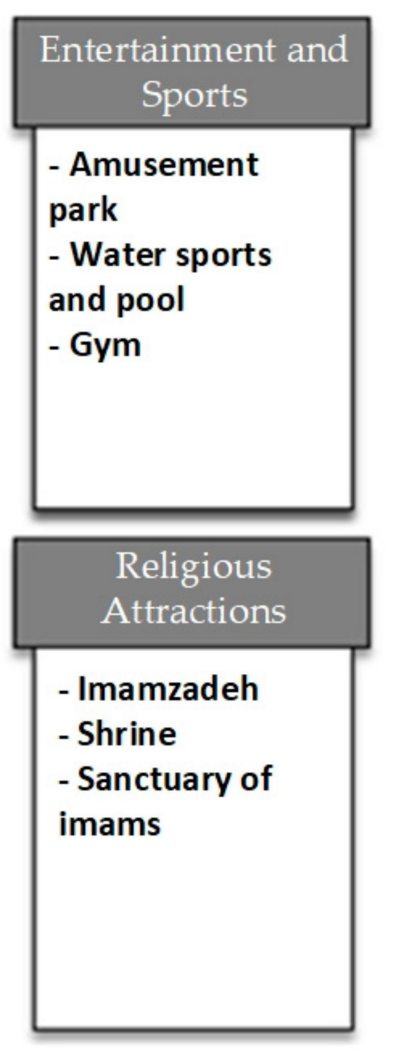

Restaurant and Fast food

\begin{tabular}{|l|}
\hline - Persian and \\
traditional food \\
- Nations food \\
- Fast food \\
- Restaurant \\
- Buffet \\
- Café
\end{tabular}

\section{Historical and} Cultural

\begin{tabular}{l|} 
- Places and \\
mansions \\
- Museum \\
- Castles \\
- Markets \\
- Old Squares
\end{tabular}

Figure 3. The tourist place categories. 
Table 1. Service time of tourist places.

\begin{tabular}{cc}
\hline Service Time & Tourist Place \\
\hline $09: 00-18: 00$ & Golestan Palace \\
08:00-16:00 & Money Museum \\
15:30-19:00/12:00-23:00 & Kenzo Restaurant \\
11:00-23:00 & Bitter Sweet Cafe \\
$09: 00-00: 00$ & Book Cafe \\
\hline
\end{tabular}

Place Type Filtering

Ranking the touristic places according to the user's demographics, location, and time context is conducted in two steps. The function and the duty of the time filter in this system are to remove the places that are out-of-service time from the user's suggestions. For this purpose, a time filter is applied to the output that was obtained from the previous step. When collecting the information, the service time for each type of tourist place is also collected and stored in a database. Some examples are given in Table 1.

After checking the service time and matching it with the user's request time, the user's position is checked. As previously mentioned, the latitude and longitude for locations of the tourist places are stored in the database. When the user submits his or her request, the latitude and longitude position of the user is taken by the system and checked on the server side around the user. From the remaining options, the ones that are in the user's privacy are displayed. For example, if the user is in a place where there is no nearby restaurant, the restaurant option will be removed from the options available for the user, and the remaining locations will be displayed.

Finally, after applying all three spatial, temporal, and contextual filters, the type of place that is suggested by the system is displayed to the user, and the users' feedback is received. If the user is satisfied with the estimated location type, the locations are then ranked.

\subsection{Ranking}

After we identify what place type the user is interested in, we rank the places that are in the vicinity of the user. In order to rank the tourist places, three criteria are considered:

- Place Score: The first criterion is the score the tourists gave to the tourist place on the social networks.

D Distance: The second criterion is the user distance from the tourist place, which involves the user's distance from the surrounding tourist places being calculated at the time of the user's request; the shorter the distance, the better the rank will be.

- Density: The third criterion is the density of the tourist places, which is identified as the proximity in this study. According to this criterion, the more tourist places that are around a place, a higher priority is displayed to the user. In fact, users prefer to travel the shortest distances in order to see the most tourist places, so the proximity factor is one of the most important factors regarding offering a tourist place to the user.

Therefore, by suggesting a tourist place, the closer it is to other tourist places, the higher its score will be on the social networks, and the shorter the user's distance will be to the place. If the displayed location type is not up to the user's satisfaction, the user will directly select a location type, and the locations will be ranked as previously described. Finally, in order to calculate the final rank of each tourist place and the priority of showing a place to the user, it is necessary to combine the criteria. For this purpose, a combination of the VIKOR and the SWARA methods was used in order to rank the tourist places, which is illustrated Figure 4. In this method, the tourist place score, the density of the tourist places, the criterion of the type of tourist place that is extracted from the machine learning method according to the user's contexts, and the three criteria of the user's distance from the tourist place are also enter into SWARAs weighting method. In this method, the most suitable tourist place is entered into the algorithm with a higher coefficient than the other 
three types of tourist places, and the weights of all four factors are calculated. After that, the calculated weights are entered into the VIKOR method.

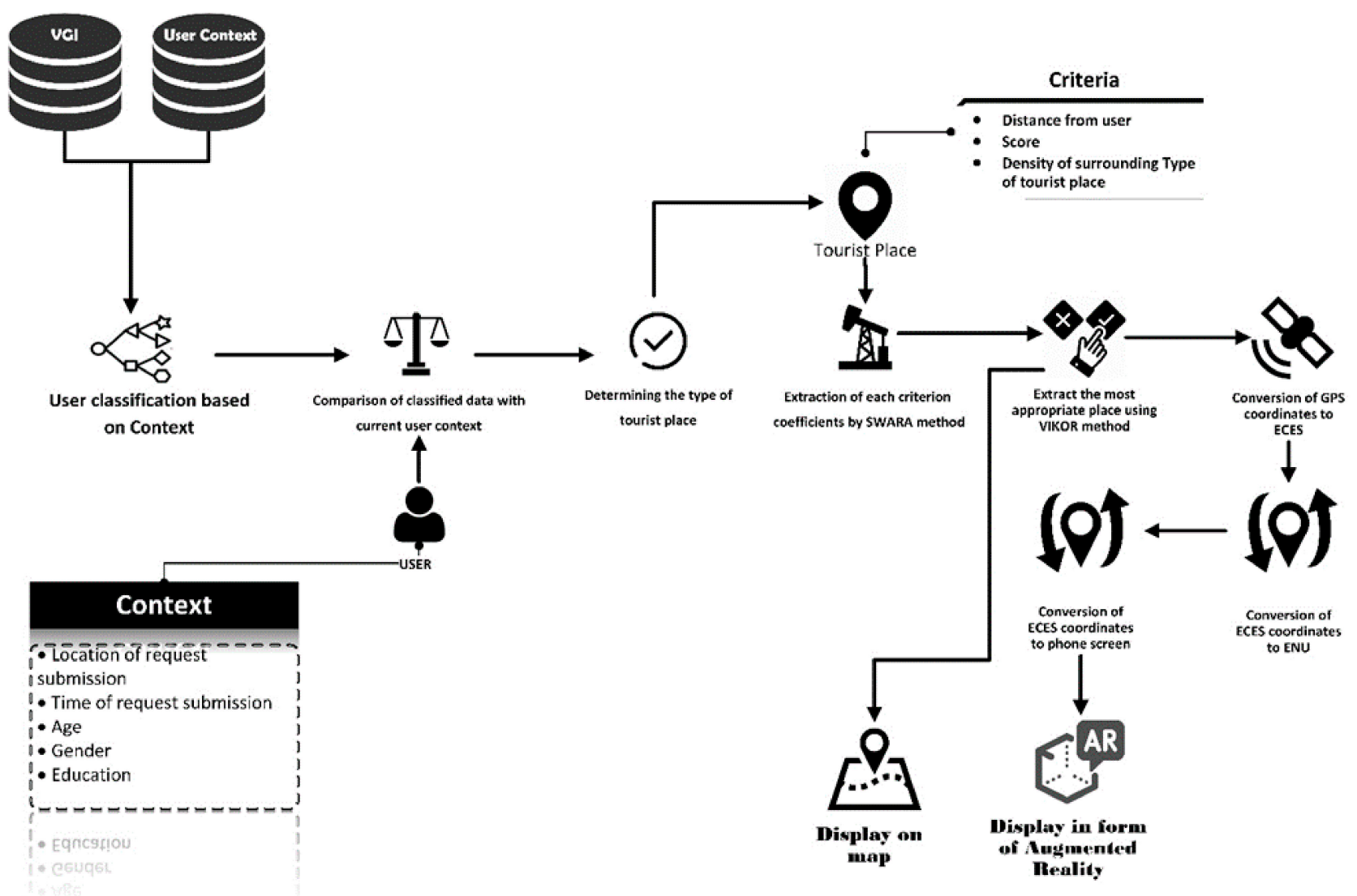

Figure 4. Ranking tourist places using the VIKOR method.

\subsection{Visualization}

Information visualization is the presentation of the data in a figurative and graphic format. This type of presentation enables the decision makers and the information holders to receive their data analysis visually. This makes it easier for them to understand the difficult concepts and to identify new patterns. In this system, no visualization is done on the proposed items, and these items are displayed only as a list, which is based on the final weight for the user in the final ranking stage. To visualize the information, two methods-the map and the AR-are used to display the information in this system.

In fact, the AR is an interface that adds the information to the real world. In the AR, the locations will be displayed to the users as the information is added to the environment. In order to display the information in the phone's coordinate system, two conversions are performed. First, the GPS coordinates are converted to the Earth-centered-Earth-fixed coordinates, and the reference ground coordinates are then converted to the navigation coordinates. Finally, the navigation coordinates are converted to the screen coordinates. In addition to the location, information such as the user's distance to the tourist location and the name of the location are added to the existing reality in the form of text. In order to display it, the order of those places that were ranked higher in the previous step will appear as a number on the phone screen. In the map display, the user-specified locations and the location of the tourist places specified in the previous step are first displayed separately on the map. The user's distance to the tourist place and the name of the tourist place are also pinned on the map when the user's location is specified. 


\section{System Development}

\subsection{Data}

The study area in this research is Tehran, which is one of the most important tourism centers in Iran. According to a recent MasterCard report, Tehran was one of the most important cities in the Middle East, Africa, and Asia in terms of tourist attractions. Tehran attracted 1.52 million tourists in 2016, and 1.79 million tourists by the end of 2017 [49]. Since it is not possible to access this type of user information on the social networks for attractive place in Tehran, the data collection was conducted using three methods, which included paper forms, applications under Android operating systems, and Google Internet forms. The information that was collected included age, gender, user-related degrees and types, names of the tourist places, the score of each place, and the users' opinions related to the tourist place.

In the paper method, the information is provided using forms that people filled out in order to provide the information. The information collected in this method included analyzing the age, personality, practice, type and name of the tourist place, the score, and the user's opinions regarding controlling the practice. In this method, the address of the tourist place is entered as the address, which needs to be manually entered and converted into the location format to latitude and longitude or the UTM coordinates. The addresses of the tourist places in the paper method need to be converted into geographical coordinates, so an application was developed in order to collect the tourist information in addition to the information that the paper form can collect. The application could also receive the coordinates of the tourist place directly in terms of the latitude and longitude. In this method, the application was prepared by the Android Studio, which was developed in the Android environment. The information entered by the tourists was collected in its database, which used the Google Firebase service. In this system, all the information that is required by the users was collected with the help of various fields embedded in the system, and the user's position was recorded using the mobile positioning sensor of a mobile phone. The online form method is also similar to the paper method, but the difference is that the online form is published on the Internet, and it uses the Google service. Publishing this form on the Internet allows for publication with much fewer restrictions than the paper form. In this case, more users have access to the form, and more information is collected at the same time. This method, which is similar to the paper method, requires the conversion of the addresses, which are entered by the users in a spatial format. Finally, after collecting the information from all three types of forms, 450 information records were collected. The spatial distribution of the data collected, which includes museums, cafes, and restaurants, is shown in Figure 5.

Finally, the data collected were prepared for further analyses in order to prevent incorrect data entries. The user rating for the tourist's location and the user's age are two items that can be checked to some extent before they are entered into the database. A person may have incorrectly scored more than 10 points for a place, which is outside the defined range, and the person may also have registered an age higher than usual. Therefore, these data require precursors in order to remove these types of additional, incorrect, or inappropriate data before it is stored in the database.

Finally, after collecting the data, it was found that the average scores the tourists gave to the tourist places, such as museums, parks, restaurants, and cafes, were 8.9, 7.8, 7.9, and 7.5 , respectively. In terms of gender, $58 \%$ of women and $42 \%$ of men went to these tourist places. $78 \%$ of the men and $22 \%$ of the women went to the park, $58 \%$ of the women and $42 \%$ of the men went to restaurants, and $79 \%$ of the women and $21 \%$ of the men went to cafes. The average age is 25 years for people that went to museums, 29 years for people who went to parks, 35 years for people that went to restaurants, and 23 years for people who went to cafes. After the wrong data were deleted, 365 records remained, which were entered into the database. 


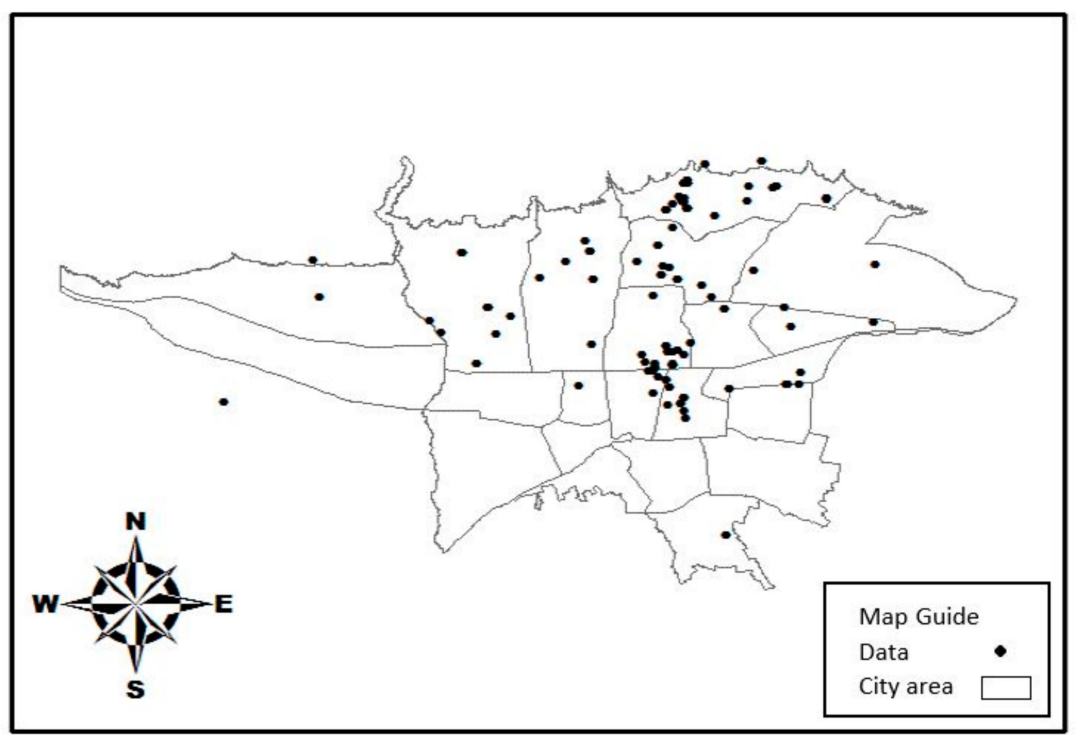

Figure 5. Spatial distribution of the data.

\subsection{The System Implementation}

In order to develop the system, WEKA software was used to classify the users, and Java and Android programming languages were used to implement the system. The use of classification algorithms reduced the questions from the users and made the system smarter. The implementation process of this system is shown in Figure 6. Figure 6 shows that after the data were collected and stored in the database, the preprocessing of the data takes place. In this study, these places were classified into three categories, which were based on the score given by the users to the tourist places. From the places that were designated as tourist places, four places, which included parks, restaurants, museums, and cafes, were selected, and the remaining items did not enter into the processing step due to the few data collected. The users' education was also coded from A to I for ease of the tree's performance, which is explained in Table 1.

\section{Collected Data}

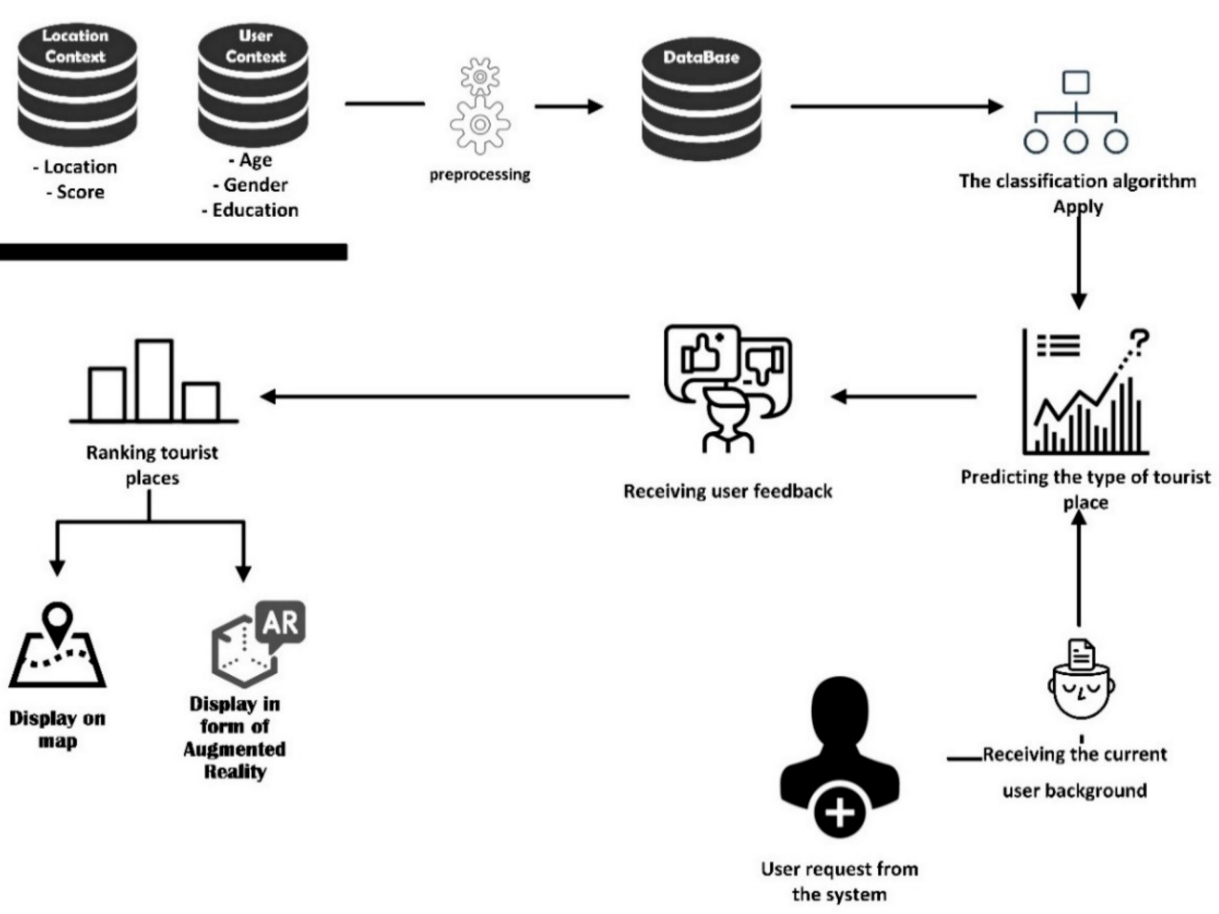

Figure 6. The implementation processes. 
In order to apply the classification algorithms on the two algorithms, the DT and SVM methods were used for this purpose. In order to implement the DT and the SVM, three columns of collected data, which included the user type, age, and the education level of the user, were entered into WEKA software. The gender column was used as a restriction in this study, and it prevented the suggestion of tourist places that have gender restrictions regarding the users. In order to identify the tourists' favorite places, the score column was used, and places with a score of higher than 7 entered the classification stage.

The data process was conducted using a J4.5 (C4.5) data mining tool and the SVM method in WEKA software. In this study, $90 \%$ of the data were considered as training data, and $10 \%$ of the data were considered as testing data. In order to determine the root of the tree in the DT method, the Entropy and Information gain indices were used. In this study, the value of the Entropy for the available data was 0.926, and the values of the Information Gain for education and age were 2.13 and 1.05. Due to the higher value of the portion of information in the education factor, this option was placed as the root in the DT.

After the classification algorithms are executed, the database data are classified and the rules are extracted accordingly. Figure 7 shows these rules. In the figure, the data are classified according to the type of tourist place, and it shows what places are visited more by people with different contexts.

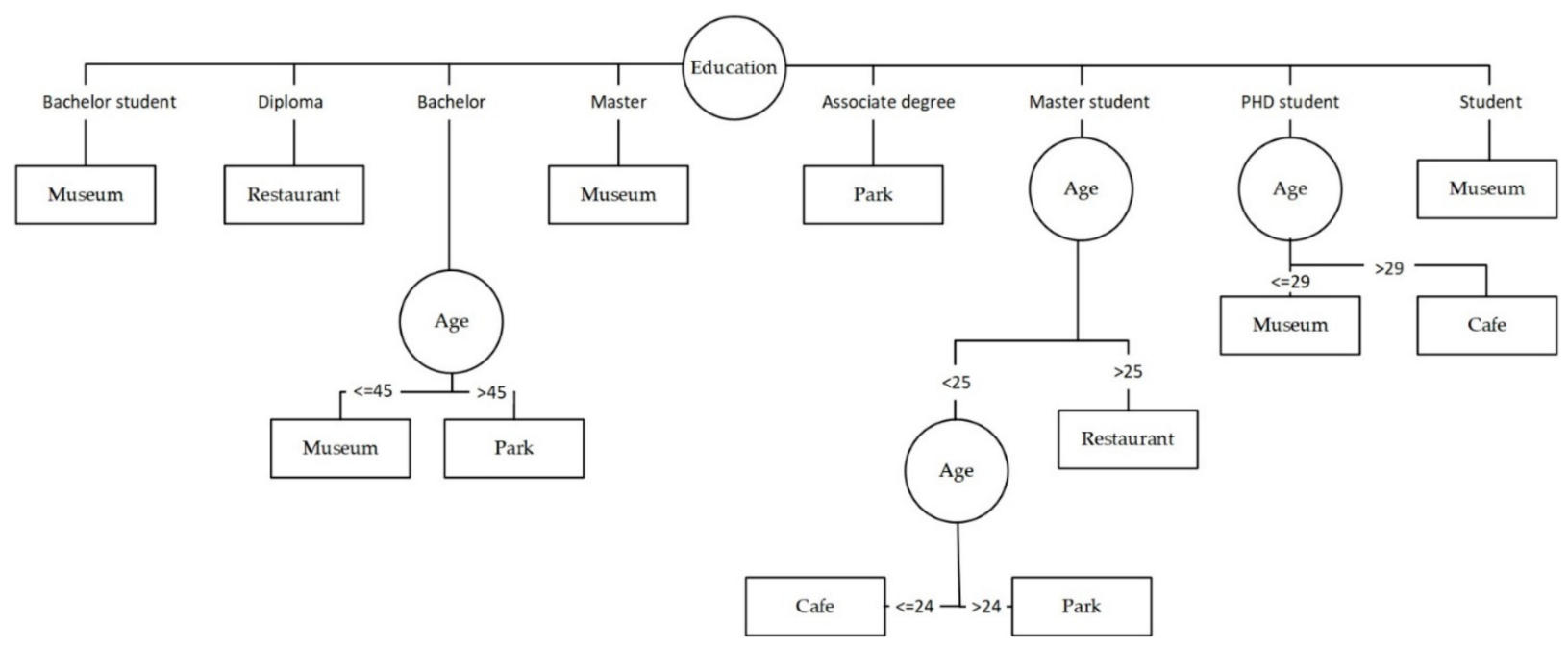

Figure 7. The result of the DT.

After classifying the data, the rules and the information extracted are stored in the database. The next step is related to the reference of the user to the system, which is shown in Figure 8a, when the user sends a request to the system. In this step, the user context is received by the system. Some of these contexts are received directly without the need of a user response, such as the request time and the user's geographical location. In addition, a number of contexts require a user response, such as age, gender, education level, and a search radius. After entering his or her information, the user can send the request to the system using two ways, which is illustrated in Figure $8 \mathrm{~b}$.

The user request procedure is shown in Figure 9. After sending the user request, the system receives the required contexts, which includes the user's position, time, and the user's context as age, gender, and level of education, and it then sends them to the server. The server receives the information from the system, and it determines the most suitable type of tourist place, as shown in Figure 10, according to the user's contexts and the rules obtained from the machine learning method (DT). 


\section{UBT our}

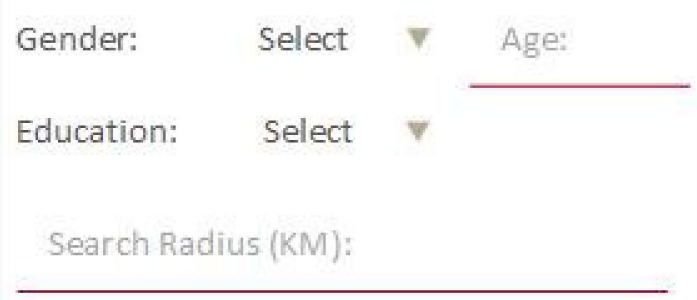

Please wait to receive coordinates:

Please wait to receive coordinates:

\section{UBITour}

Gender: $\quad$ Male $\quad \nabla \quad 28$

Education: Bachelor student

10

35.76505346

51.40526857

\section{Recommend}

\section{Recommend}

(a)

(b)

Figure 8. (a) The system home page and (b) an example of the information filled in for the system.

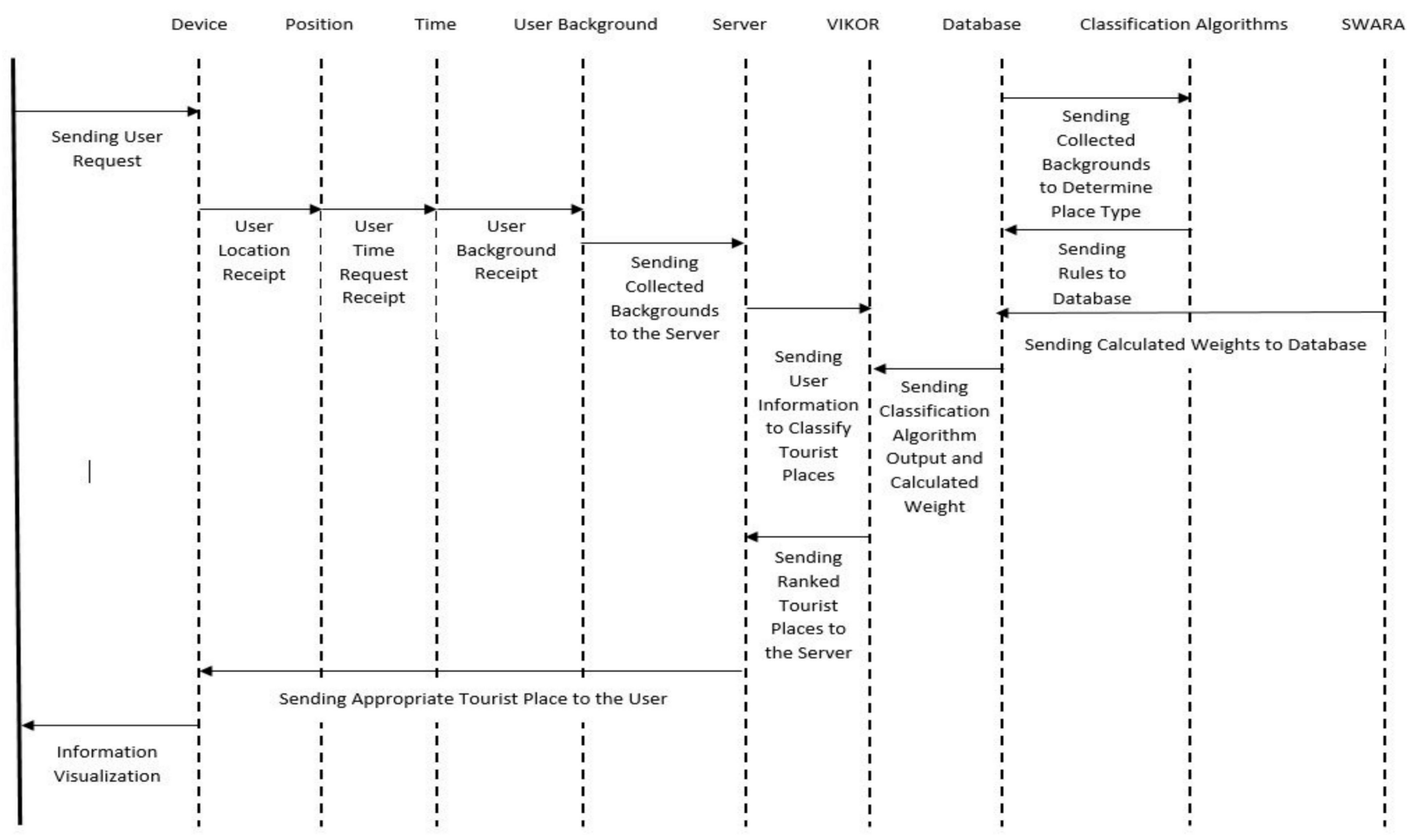

Figure 9. The user request and the server response for the VIKOR-SWARA method. 


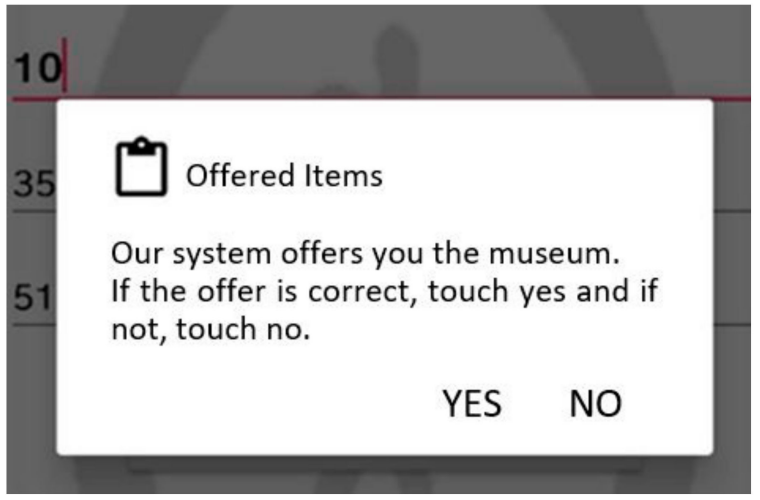

Figure 10. The initial server response to the user.

In the next step, the server needs to choose the best one among the locations in a POI type. For this purpose, the contexts need to be integrated. In order to integrate the information, four criteria, which include the buffer, proximity, score, and type of tourist place, are used. The weight of each criterion is calculated using the SWARA method. The first step in this method is to screen the criteria and sieve the criteria. After identifying the most important indicators in accordance with the experts' opinions, the indicators are identified and ranked in the order of importance. Based on their importance, these indicators are ranked based on the opinions of 5 GIS experts and 30 tourists. Determining the relative importance of each indicator is the next step. In this step, the relative importance of each indicator toward the more important previous indicator needs to be determined, which is determined by the experts' opinions. The next step is to calculate the coefficient, which is obtained by adding the relative importance of each criterion to the value of one. The fourth step is to calculate the initial weight obtained by dividing the coefficient calculated in the standard step by the coefficient calculated in the next criterion. In this part, the initial weight of the first indicator, which is the most important criterion, is equal to one. The last step is to calculate the final weight, which is the normalized weight, and it is calculated by dividing the initial weight of each factor by the sum of the total initial weight. Table 2 shows the relevant calculations. Finally, the last normal weight is multiplied by 10 in order to make them more appropriate for the implementation.

Table 2. Weight calculated for each criterion using the SWARA method.

\begin{tabular}{ccccc}
\hline Step 1 & Step 2 & Step 3 & Step 4 & Step 5 \\
\hline Place Type & 1 & 1 & 1 & 0.456 \\
Score & 0.7 & 1.7 & 0.588 & 0.267 \\
Proximity & 0.6 & 1.6 & 0.367 & 0.166 \\
Distance & 0.5 & 1.5 & 0.245 & 0.111 \\
\hline
\end{tabular}

After calculating the weight of each factor, extracting the rules from the algorithm of the DT and also receiving the user contexts, this information is entered into the VIKOR method in order to use it for the tourist places classification. In this step, four sample places, which included Cafe Lamiz, Cafe Menro, Cafe Kenzo, and the Hatam Restaurant, were used to determine the best tourist place for a 25-year-old male user with a master's degree education. The results of the VIKOR are shown in Table 3. 
Table 3. The results of the VIKOR method.

\begin{tabular}{ccccc}
\hline & $S_{\boldsymbol{i}}$ & $\boldsymbol{R}_{\boldsymbol{i}}$ & $\boldsymbol{Q}_{\boldsymbol{i}}$ & Ranking \\
\hline Lamiz & 0.3246 & 0.2136 & 0 & 1 \\
Menro & 0.35 & 0.267 & 0.143 & 2 \\
Kenzo & 0.505791 & 0.267 & 0.349 & 3 \\
Hatam & 0.703255 & 0.456 & 1 & 4 \\
\hline
\end{tabular}

For the final ranking, conditions $\mathrm{C} 1$ and $\mathrm{C} 2$ must to be considered. In the case of the first condition, the value of Q2-Q1 is equal to 0.143 , which is less than 0.33 , and it is the result of one, which is the one-number option. Therefore, condition $\mathrm{C} 1$ is not met. Furthermore, the value of $m$, which is the maximum value that holds for $Q$ (A_m) - $Q$ (A_1) $<1 /(j-1))$, must be calculated. For our problem, the value is two. In addition, the Lamiz and Menro options are known as the top options.

The next step is to visualize the information. In order to visualize the information, two tools, which include a map and the AR, were used. For visualization in the map platform, the ArcGIS SDK for an Android library was used. In this part, the tourist coordinates received by the system were first displayed on the map. On the other hand, the coordinates of the final POIs that were specified in the previous step and the information, such as the user's distance to the tourist place, type of tourist place, and name of the tourist place, were also specified on the map, which is shown in Figure 11.

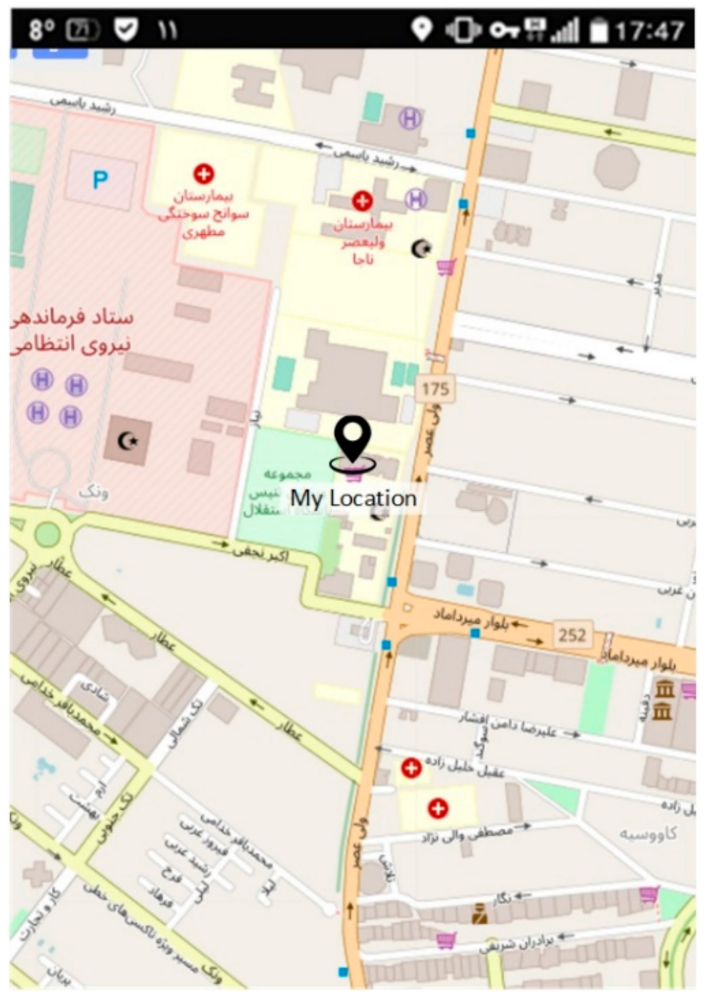

(a)

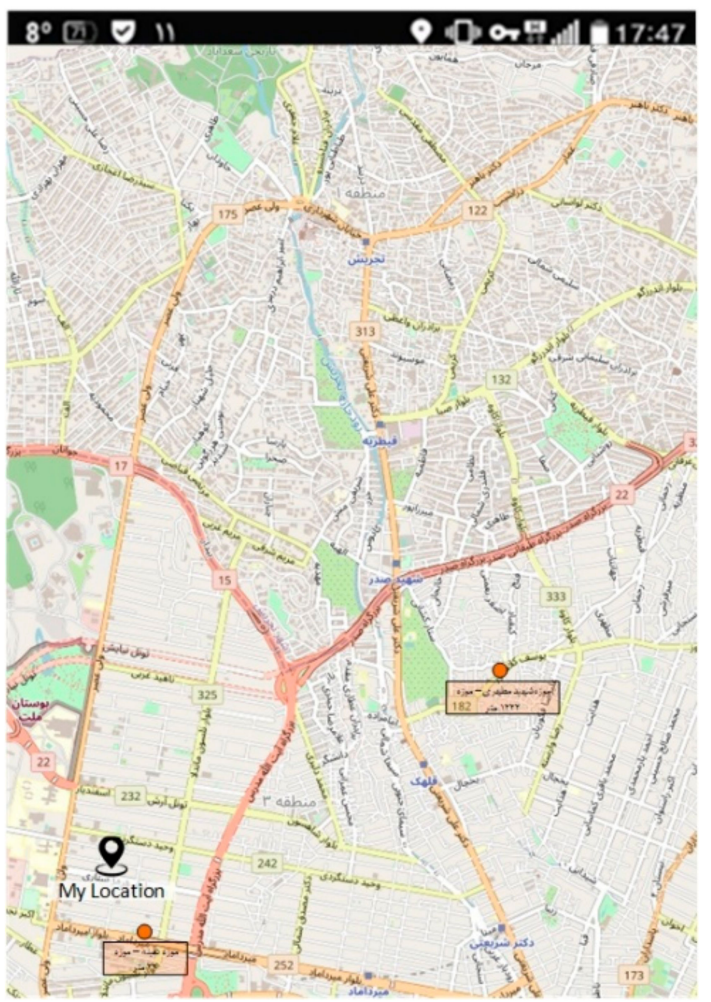

(b)

Figure 11. (a) The user position display and (b) the tourist places display.

With the visualization using the AR, the AR location-based package is used. The type of AR used in this study was the base sensor, and it uses the position to add information and to identify the location. The AR transfers the real coordinate system to the camera coordinate system, which the real coordinate system is the geographic coordinate system in this library. In this package, the geographical coordinates of the points, which are 
the latitude and longitude, are converted to the navigation coordinates ( $x$ and $y$ ), and the navigation coordinates are then converted to the camera coordinates and displayed in points on the camera screen.

In this study, the coordinates of each tourist place are entered into the AR class after the best items in the previous step are identified. In addition, after the relevant transformations are performed, the location is added to the environment as the AR. At first, by using the sensors inside the mobile device, the user's position is calculated as a latitude and longitude when the user enters the environment. Afterward, the system uses the user contexts in order to estimate the type of appropriate tourist place by using one of two methods, which includes the VIKOR method. After that, it converts the coordinates of the tourist place from the GPS coordinates, which are the latitude and longitude, by performing several conversions, which were previously described, to the phone screen coordinates. Among the items that are displayed to the user as the AR, the first item with the highest score is added to the environment, and the following items are added in order. The priority of each item is displayed to the user as a number, which is illustrated in Figure 12.

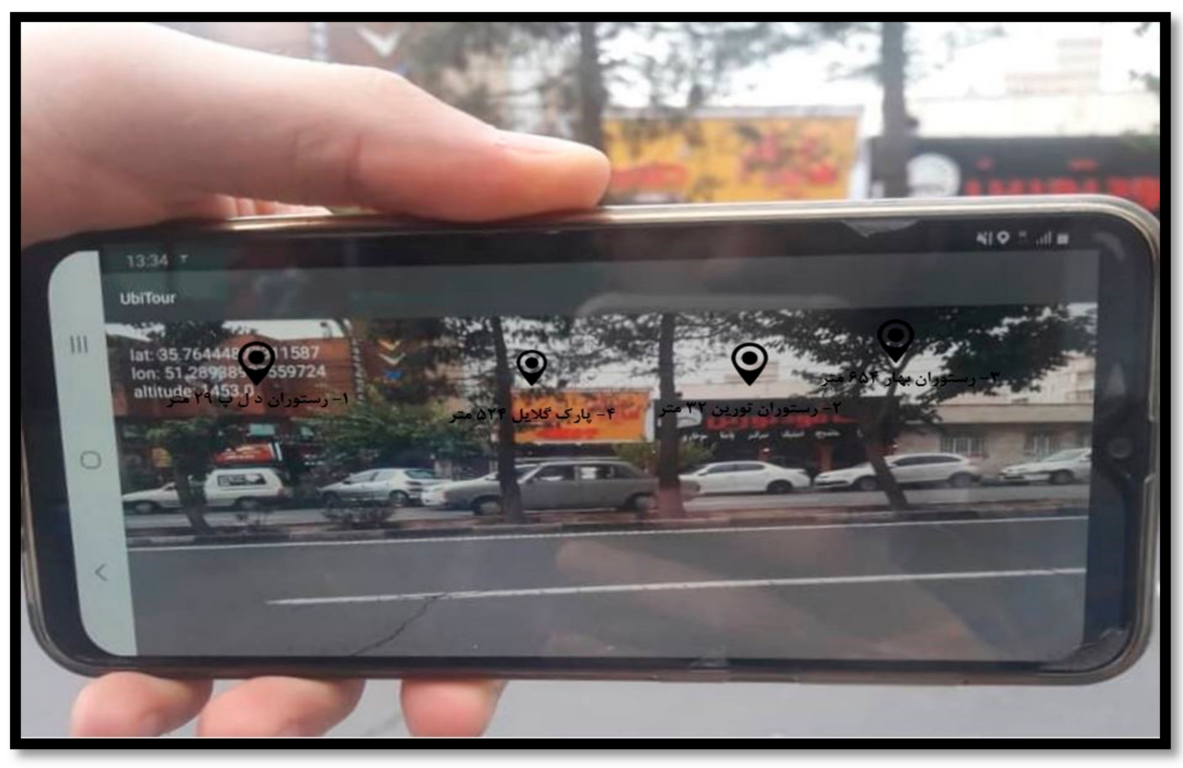

Figure 12. Visual display of the information in an AR format.

In Figure 12, the places suggested to the user, which are restaurants and parks, are prioritized. The two restaurants, which include D.L.P. and Turin, are located closer to the user and are within the user's sight. Mehr restaurant and Gelayol Park are far from the user and are not in the user's sight. In this system, by using the information provided by the AR to the user, the user is allowed at any time to receive the location and the direction of the restaurant and park according to his or her current location. Moreover, the user's confusion regarding finding the exact location of the restaurant and the problems that a map can create for the user, which is due to the user centric in the AR, are prevented.

\section{Evaluation}

In this section, the system implemented needs to be evaluated to check its efficiency and accuracy. Two main parts of the system are evaluated. One is the prediction evaluation by the Decision Tree (DT) [50] and Support Vector Machine (SVM) [51] methods, and the other method is the AR part, which is the level of user satisfaction with the system. For the prediction evaluation, the root mean square error, precision, recall, overall accuracy, and kappa indicators are provided. For the user study, a questionnaire [52] is used to evaluate the ease-of-use and the usefulness of the system. 


\subsection{Perdiction Evaluation}

With the implementation of the data analysis methods, which include the DT and SVM methods, $90 \%$ of the data are considered as training data, and $10 \%$ of the data are considered as testing data. In order to check the results, three statistical indicators were used, which include correctly classifying the instances, the root mean square error calculated by using Equation (13), and the mean absolute error calculated by using Equation (14).

$$
\begin{aligned}
\text { xRMSE } & =\sqrt{\frac{1}{n} \sum\left[y_{i}-x_{i}\right]^{2}} \\
M A E & =\frac{\sum_{i=1}^{n}\left|x_{i}-y_{i}\right|}{n}
\end{aligned}
$$

In Table 4, the DT method shows better performance among all three identified factors. Another way to evaluate it is to use the space under the recall-precision curve. The larger the space under the PR chart, the higher the values of the precision and the recall. A high amount of accuracy indicates a false positive, and a high amount of recall indicates a false negative. Therefore, the graph above the other diagram shows better performance than the other method. Figure 13 shows the recall-precision diagram for both the SVM and the DT methods. According to the diagram, the DT is higher than the SVM diagram in all parts.

Table 4. Results of the DT and SVM.

\begin{tabular}{cccc}
\hline & $\begin{array}{c}\text { Root Mean Square } \\
\text { Error }\end{array}$ & $\begin{array}{c}\text { Percentage of Correctly } \\
\text { Classified Instances }\end{array}$ & $\begin{array}{c}\text { Mean Absolute } \\
\text { Error }\end{array}$ \\
\hline SVM & 0.361 & 73.75 & 0.285 \\
J84 & 0.287 & 77.5 & 0.164 \\
\hline
\end{tabular}

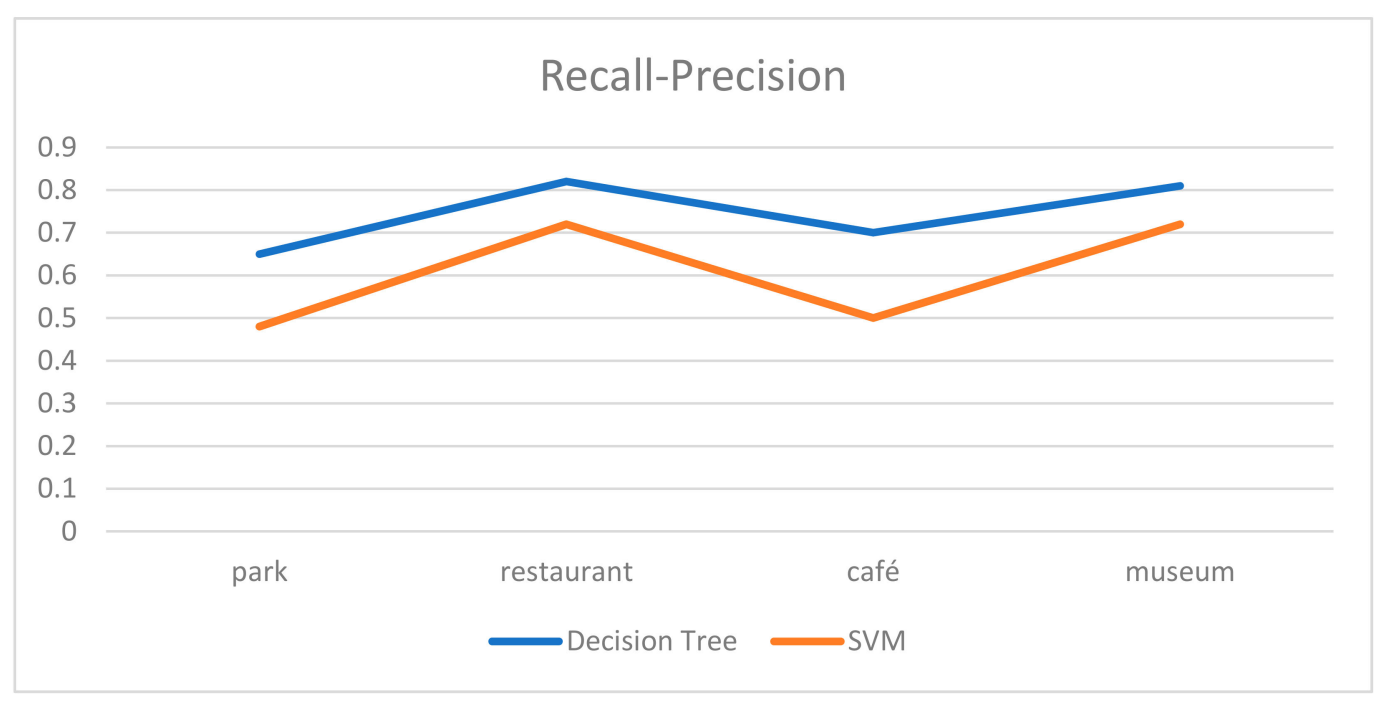

Figure 13. Recall-precision chart.

Another indicator that is used in this study to evaluate the performance of the two DT and SVM methods, is the classification error matrix, which is shown in Table 5. In Table 5, the DT also showed better performance with this indicator. It performed better than the SVM in the three types of park and restaurant locations, but it performed worse than the SVM only with the cafe floor. The overall accuracy indicator can be used in order to review Table 3 in a more detailed manner. The overall accuracy is calculated by the sum of the original diameter numbers of the error matrix divided by the sum of the total numbers 
of the matrix. which is calculated using Equation (15). The overall accuracy calculated for the DT is $77 \%$ and $73 \%$ for the SVM method.

$$
\text { Overall accuracy }=\frac{1}{n} \sum p_{i i}
$$

Table 5. The classification error matrix.

\begin{tabular}{ccccccccc}
\hline & \multicolumn{2}{c}{ Museum } & \multicolumn{2}{c}{ Cafe } & \multicolumn{2}{c}{ Restaurant } & \multicolumn{2}{c}{ Park } \\
\hline & SVM & DT & SVM & DT & SVM & DT & SVM & DT \\
\hline Park & 6 & 6 & 3 & 1 & 0 & 1 & 5 & 6 \\
Restaurant & 1 & 1 & 3 & 0 & 11 & 14 & 0 & 0 \\
Cafe & 3 & 3 & 11 & 10 & 1 & 2 & 0 & 0 \\
Museum & 32 & 32 & 3 & 3 & 1 & 1 & 0 & 0 \\
\hline
\end{tabular}

According to the drawbacks of the overall accuracy method, the kappa indicator was used to ensure the accuracy. The kappa indicator was calculated using Equation (16), which gives 0.667 for the DT and 0.611 for the SVM.

$$
\text { kappa }=\frac{p_{o}-p_{c}}{1-p_{c}} * 100
$$

where $p_{o}$ is the correct classified observational pixels, and $p_{c}$ is the expected agreement about the pixels.

\subsection{System Evaluation}

In order to evaluate the final function of the system from the users' point of view, this system was reviewed by the tourists from two perspectives, which include the easiness and the usefulness of the system. For this purpose, the method used in the system, which was implemented by 30 tourists, was reviewed and evaluated. After teaching the people how to work with the system, they were asked questions about using the system that were based on the map that was implemented and the system (Table 6). The questions were asked in two categories, which included the easiness and the usefulness of the system [52]. In order to perform this evaluation, the following form was prepared, and the tourists and the users of the system were asked to carefully complete this form.

Table 6. System Evaluation Form.

Age:

Q.1. Are you familiar with augmented reality technology?

Q.2. Are you familiar with location-based systems?

The ease-of-use checking

Q.3. How simple does the current system provide the information for you?

Q.4. To what extent does the current system lead you to a specific location?

Q.5. To what extent does the current system select an appropriate POI for you?

Q.6. How easy it is to use and learn this system? System usefulness checking

Q.7. How attractive is the display of information in the AR format?

Q.8. To what extent are you willing to use this system?

Q.9. To what extent does the system help you find a tourism POI?

$\begin{array}{lllll}\text { Gender: } & & \text { Male } \square & \text { Female } \square & \text { Education: } \\ \text { Yes } \square & & \text { No } \square & & \\ \text { Yes } \square & & \text { No } \square & & \\ \text { Very Good } \square & \text { Good } \square & \text { Normal } \square & \text { Poor } \square & \text { Very Poor } \square \\ \text { Very Good } \square & \text { Good } \square & \text { Normal } \square & \text { Poor } \square & \text { Very Poor } \square \\ \text { Very Good } \square & \text { Good } \square & \text { Normal } \square & \text { Poor } \square & \text { Very Poor } \square \\ \text { Very Good } \square & \text { Good } \square & \text { Normal } \square & \text { Poor } \square & \text { Very Poor } \square \\ \text { Very Good } \square & \text { Good } \square & \text { Normal } \square & \text { Poor } \square & \text { Very Poor } \square \\ \text { Very Good } \square & \text { Good } \square & \text { Normal } \square & \text { Poor } \square & \text { Very Poor } \square \\ \text { Very Good } \square & \text { Good } \square & \text { Normal } \square & \text { Poor } \square & \text { Very Poor } \square\end{array}$


The statistical results of this survey are shown in Table 7 and Figures 14 and 15. The first criterion evaluated in this table is the standard deviation. The standard deviation values that were calculated indicate a small difference between the values of this evaluation and the average of the numbers. The highest rate for the standard deviation in the VIKOR method is 0.855 . The lowest rate is related to question number 7 , which has a value of 0.568 . Moreover, this factor also has the highest user satisfaction, which is shown in Figure 15, and it could be due to the high attractiveness of the AR for the tourists. Other criteria include the lower quartile, the middle quartile, the upper quartile, and the interquartile range. These three criteria divide the data collection into four parts. The lower quartile is the data from the area where $25 \%$ of the total data is smaller and $75 \%$ of the data is larger. For the middle quartile, these numbers are $50 \%$, and for the upper quartile, the data are $75 \%$ smaller and $25 \%$ larger. The interquartile range is an indicator of the scatter that calculates the difference between the 25th and 75th percentiles, and the presence of a small number of very large or very small observations does not affect this criterion [53]. The lower quadrant is 4 in all the questions and 5 for the upper quadrant, which results in a quadratic range value of 1 for all the questions. This indicates the high user satisfaction.

Table 7. Results of the statistical evaluation of the system.

\begin{tabular}{cccccccc}
\hline & Q3 & Q4 & Q5 & Q6 & Q7 & Q8 & Q9 \\
\hline Standard Deviation & 0.727 & 0.770 & 0.795 & 0.678 & 0.568 & 0.569 & 0.855 \\
Lower Quarter & 4 & 4 & 4 & 4 & 4 & 4 & 4 \\
Middle & 5 & 5 & 5 & 5 & 5 & 5 & 5 \\
Higher Quarter & 5 & 5 & 5 & 5 & 5 & 5 & 5 \\
Intermediate Range & 1 & 1 & 1 & 1 & 1 & 1 & 1 \\
Skewness & -0.902 & -0.854 & -0.712 & -0.804 & -0.888 & -0.740 & -0.740 \\
Kurtosis & -0.473 & -0.730 & -1.072 & -0.402 & -0.168 & -0.462 & -1.400 \\
\hline
\end{tabular}

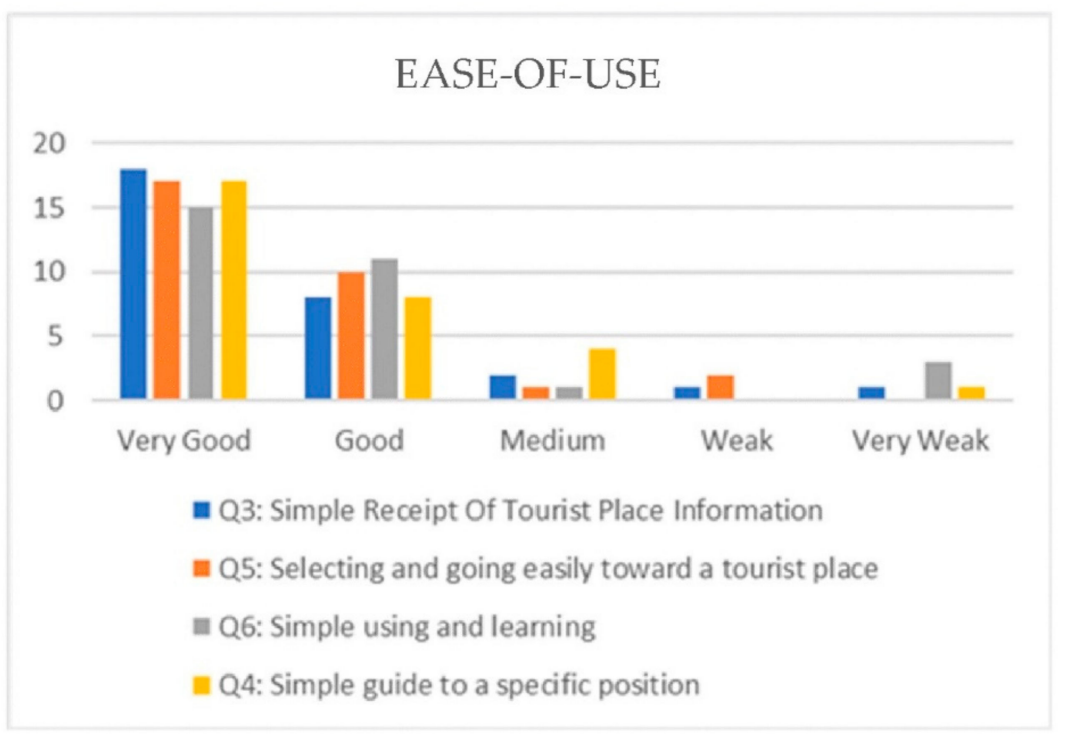

Figure 14. Reviewing the user satisfaction level based on the ease-of-use criteria. 


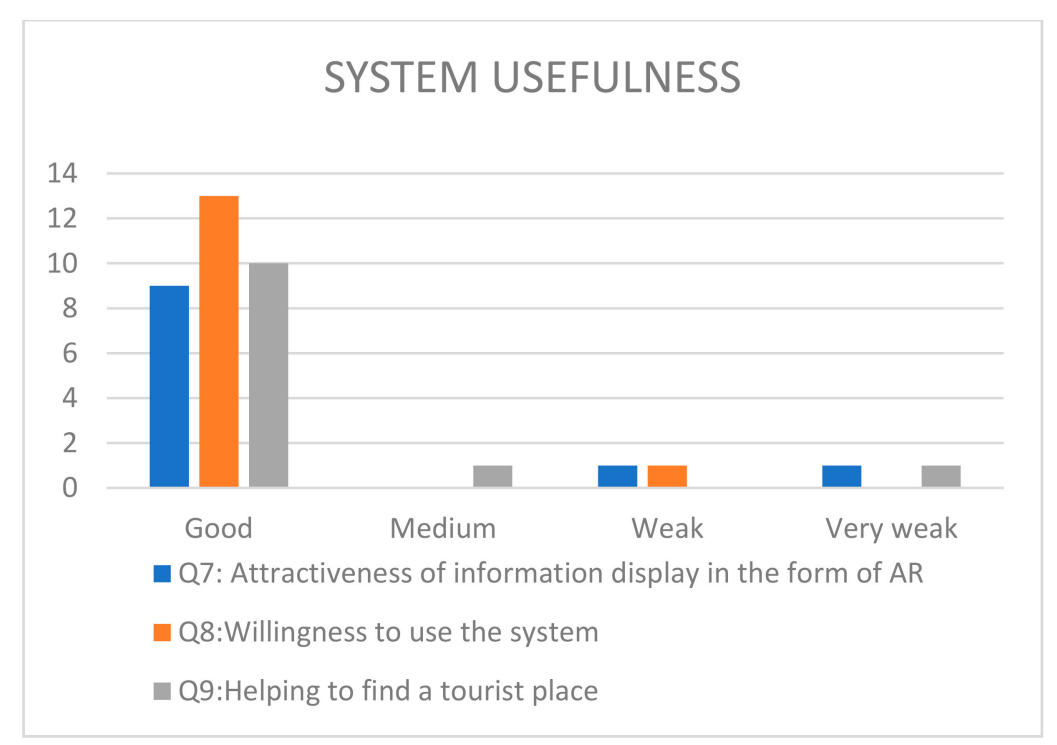

Figure 15. Reviewing the user satisfaction level based on the system usefulness criteria.

The skewness in the statistics indicates the degree of asymmetry of the possible distribution. If the data are symmetric to the mean, the skewness will be zero. If the amount of skewness is greater than zero, the skew is to the right, and if it is less than zero, the skew is to the left. In left-sided skew, the left tail is longer than the right tail, so more data volume is concentrated on the right, and the curve seems to be curved to the right. In Tables 4-7, the skewness of the collected data is calculated in order to evaluate the system, and it shows that the skewness of the data is negative, and its values are between -0.6 and -0.9 , which indicates that the greater volume of data is on the right, which displays a high level of user satisfaction. The highest amount of skewness in the ease-of-use criteria is related to question number 3, which is related to question Q7 in the usefulness of the system criteria. These two factors also have a highest user satisfaction level, as shown in Figures 14 and 15, which are indicated by the high data density in the high numbers, and it also indicates a high user satisfaction level.

The kurtosis is also one of the scattering indicators, which is also one of the distance indicators. This indicator determines the degree of concentration, scatter, and the kurtosis of the data of a frequency distribution. In other words, the kurtosis indicates how wide or peaked the distribution is. When the value is more than zero, the stretch is positive. In this case, the distribution of the scores is more elongated than the normal curve. In a positive kurtosis, the scores are close to the average. The kurtosis is negative when its value is less than zero, which in this case, the shape of the curve is shorter than the normal curve, and it becomes oblique. In general, if the skewness and the kurtosis are not in the range $(2,-2)$, the data will not have a normal distribution.

The ease-of-use of the system is evaluated in Figure 14. In terms of the ease-of-use of the system, the users are the most satisfied with receiving the tourism information from the system. Due to the fact that this part of the system is presented in two forms, which includes a map and the AR, it is very attractive for the users, and it has a high percentage of satisfaction, as expected, which is $60 \%$ among the users. Among the users who evaluated the system, only $53 \%$ of the users were familiar with the AR, so the least satisfaction is related to learning the system, which is because of the fact that the AR is still not recognized as a common technology among the users, and it causes confusion for some, which was predictable. This part eventually achieved a 50\% user satisfaction. Finally, the criterion of the ease-of-use of the system was studied in general. In this evaluation, $55 \%$ of the users on average evaluated the criterion of the ease-of-use of the system as very good, $32 \%$ as good, $5 \%$ as normal, $3 \%$ as poor, and $3 \%$ as very poor. 
Another criterion considered for the general evaluation of the system by tourists and the users is the criterion of the usefulness of the system, which is illustrated in Figure 15. In this evaluation, this criterion has the highest user satisfaction level of $60 \%$, which is due to the fact that the display of the information is in a format, and it is still new for the users and the tourists in augmented reality. Because of the users' unfamiliarity with the AR, how to work with AR systems, and also the newness of this technology, the lowest level of satisfaction in this criterion is related to the criterion that involves the willingness to use this system, which had a satisfaction level of 53\%. With the general evaluation of this criterion, it is obvious that $56 \%$ of the users generally evaluated the usefulness criterion of the system as being very good, 37\% stipulated it as good, 1\% evaluated it as normal, $2 \%$ indicated it is poor, and $2 \%$ regarded it as very poor.

\section{Discussion}

Safoury et al. [14] and Wang et al. [15] presented a developed system that could solve the cold-start problem by using demographic information. By using demographic information, we can visualize personalized information for any user without the need to have the user's history. Therefore, the proposed methodology improved the personalized visualization and can be combined with the existing content and collaborating filtering methods, which were utilized in some literature for developing personalized AR systems. Although the literature covers using demographic contexts for personalization, this research addressed combining the demographic and spatial-temporal contexts in order to develop the AR system. The AR system is utilized in real-time and in the real-world, so applying spatial-temporal contexts were necessary in order to develop the AR system. As a result, our methodology adapted the existing method for the AR system by combining the demographic and spatial-temporal contexts

Comparison of the results of two machine learning methods, which include the DT and SVM methods, showed better performance with the SVM method by about 6\% in regard to the overall accuracy. Furthermore, the high accuracy of the prediction of the user preferences, which were more that $70 \%$ for both methods, prove the relation between the user's interest in the touristic attractions and demographic contexts, which include age, gender, and education level. According to this result, better performance will be obtained if we collect more data for the training and testing methods. In addition, the user study results showed a high level of the user satisfaction, which is a more that $70 \%$ agreement. It indicates that the proposed methodology is toward developing ubiquitous GIS systems, because the ease-of-use and context-awareness are the two main features of the ubiquitous GIS systems. The demographic contexts made it possible to provide the right information to the user, and the spatial-temporal contexts enabled us to provide the right service at the right location and the right time. The AR technology made the use and learning of the tourism system more convenient by creating a natural and 3D user interface.

Although we believe that this research provides value in the field of personalized AR tourism systems, it has some limitations. First, the user feedback was applied only for changing the place type, which the user is interested in, whereas it can be used in the learning process by using a reinforcement learning method in order to improve the prediction accuracy. Second, this research focused on the spatial ranking to visualize the touristic attractions through the personalized AR system according to the user's preferences and the spatial-temporal criteria. However, the AR system requires semantic ranking in addition to spatial ranking in order to rank the contents at each recommended tourism place. At each place, there are various contents that are valuable to provide to the tourists. For instance, the various contents of restaurants include menus, customer satisfaction, the restaurant capacity, and the crowdedness of the restaurant. These various contents should be ranked according to the user's preferences in the AR systems. Finally, this research can be improved by combining it with routing methods $[30,54]$ so that the user can be navigated to the ranked PoIs. 


\section{Conclusions}

In this study, the concepts of a tour guide system in the GIS, which enriches the AR data by using the big spatial data, and the studies in this area are researched. In this research, a context-aware model to promote the AR-based tourism program was introduced and evaluated in order to develop a personalized AR based tour guide system. This system uses the time, position, score, age, and gender contexts to manage the high volume of data by using the VIKOR-SWARA method in order to combine these contexts and rank the tourist places that are suggested to the user.

The results of this study are reviewed in two parts: evaluation of the machine learning results and the system evaluation. In the machine learning part, the results show better and more accurate performance with the DT than the SVM. In the studies that were conducted, the root mean square error for the DT is 0.287 and 0.361 for the SVM. In addition, the correct classified items for the DT were calculated to be $77.5 \%$ in this study, which used the percentage criterion. For the SMV, it was calculated to be $73.75 \%$. In the case of the absolute mean error, the DT again had better accuracy (0.164) than the SVM (0.285). Another criterion that was considered to evaluate these two methods was the precisionrecall chart. In this criterion, the DT diagram was also completely above the SVMDe diagram, which indicated better performance of the DT. Another indicator studied in this section was the classification error matrix, which was the overall accuracy criterion used to accurately study the table. The indicator rate for the DT was $77 \%$ and $73 \%$ for the SVM method.

With the general evaluation of the system, the first users' opinions were studied using the statistical indicators. The first criterion had a standard deviation of 19, which the calculated standard deviation values show a small difference between the values of this evaluation and the average of the numbers. The highest amount for the standard deviation was related to question 9, which had a value of 0.844 , and the lowest value was related to question 7 , which was 0.568 . This question had the highest level for the user's satisfaction regarding the ease-of-use, which can be due to the high attractiveness of the AR for the users. The next criteria are the lower quartile, the middle quartile, the upper quartile, and the interquartile range. With the evaluation of these four criteria, it was determined that the lower quartile and the middle quartile for all the questions is 4 , and the upper quartile is 5 , which leads the value of the interquartile range for all the questions to be 1 . This indicates that the answers are close for all of the users, and it also shows their high satisfaction level. The next criterion was the data skewness. By studying and calculating this criterion, it was found that the data skewness was negative, and its amount was between -0.6 and -0.9 , which indicates that the volume and the concentration of more data on the right, illustrating the users' high satisfaction level. The highest amount of skewness was related to question 3 and 7. In addition, by evaluating the ease-of-use and the usefulness of the system, these two questions had the highest user satisfaction, which generally indicates the high data density in the high numbers, which is high user satisfaction.

The last criterion is studying the ease-of-use and the usefulness of the system. By studying these two criteria, it was found that the overall satisfaction of the users in terms of the ease-of-use was $55 \%$, which was the highest amount and related to the simple receipt of information, which had a satisfaction rate of $60 \%$. From the point of view of the usefulness of the system, the overall satisfaction of the tourists evaluated was $56 \%$, and the highest value of this criterion was related to the attractiveness of the information display in the form of the AR, which had a $60 \%$ satisfaction rate. The study of these two criteria shows the desired level of the user's satisfaction with this system.

Author Contributions: Conceptualization, S.R. and A.S.-N.; Formal analysis, S.R. and M.S.; Funding acquisition, S.-M.C.; Investigation, S.R.; Methodology, S.R., A.S.-N. and M.S.; Project administration, S.-M.C.; Resources, A.S.-N.; Software, S.R.; Supervision, A.S.-N.; Validation, A.S.-N.; Visualization, M.S.; Writing—original draft, S.R. and M.S.; Writing—review \& editing, A.S.-N. and S.-M.C. All authors have read and agreed to the published version of the manuscript. 
Funding: This research was supported by the MSIT (Ministry of Science and ICT), Korea, under the ITRC (Information Technology Research Center) support program (IITP-2021-2016-0-00312) supervised by the IITP (Institute for Information \& Communications Technology Planning \& Evaluation).

Institutional Review Board Statement: Not applicable.

Informed Consent Statement: Not applicable.

Data Availability Statement: Data available on request due to restrictions eg privacy or ethical.

Conflicts of Interest: There is no conflict of interests.

\section{References}

1. Georgievski, I.; Aiello, M. Automated Planning for Ubiquitous Computing. ACM Comput. Surv. 2017, 49, 1-46. [CrossRef]

2. Kim, H.; Matuszka, T.; Kim, J.I.; Kim, J.; Woo, W. Ontology-based mobile augmented reality in cultural heritage sites: Information modeling and user study. Multimed. Tools Appl. 2017, 76, 26001-26029. [CrossRef]

3. Kourouthanassis, P.; Boletsis, C.; Bardaki, C.; Chasanidou, D. Tourists responses to mobile augmented reality travel guides: The role of emotions on adoption behavior. Pervasive Mob. Comput. 2015, 18, 71-87. [CrossRef]

4. Han, D.-I.; Dieck, M.C.T.; Jung, T. User experience model for augmented reality applications in urban heritage tourism. J. Herit. Tour. 2018, 13, 46-61. [CrossRef]

5. Shin, C.; Hong, S.-H.; Yoon, H. Enriching Natural Monument with User-Generated Mobile Augmented Reality Mashup. J. Multimedia Inf. Syst. 2020, 7, 25-32. [CrossRef]

6. Balduini, M.; Celino, I.; Dell'Aglio, D.; Della Valle, E.; Huang, Y.; Lee, T.; Kim, S.-H.; Tresp, V. BOTTARI: An augmented reality mobile application to deliver personalized and location-based recommendations by continuous analysis of social media streams. J. Web Semant. 2012, 16, 33-41. [CrossRef]

7. Torres-Ruiz, M.; Mata, F.; Zagal, R.; Guzmán, G.; Quintero, R.; Moreno-Ibarra, M.J.V.R. A recommender system to generate museum itineraries applying augmented reality and social-sensor mining techniques. Virtual Real. 2020, 24, 175-189. [CrossRef]

8. Tarantino, E.; De Falco, I.; Scafuri, U. A mobile personalized tourist guide and its user evaluation. Inf. Technol. Tour. 2019, 21, 413-455. [CrossRef]

9. Ji, Y.; Tan, P.; Duh, H.B.-L. Research on Personalized Learning Pattern in Traditional Handicraft Using Augmented Reality: A Case Study of Cantonese Porcelain. In Proceedings of the International Conference on Human-Computer Interaction, Palma, Spain, 12 September 2018; pp. 304-316.

10. Garcia, A.; Torre, I.; Linaza, M.T. Mobile Social Travel Recommender System. In Information and Communication Technologies in Tourism 2014; Springer: Berlin/Heidelberg, Germany, 2013; pp. 3-16.

11. Bahramian, Z.; Abbaspour, R.A.; Claramunt, C. A Cold Start Context-Aware Recommender System for Tour Planning Using Artificial Neural Network and Case Based Reasoning. Mob. Inf. Syst. 2017, 2017, 1-18. [CrossRef]

12. Colomo-Palacios, R.; García-Peñalvo, F.J.; Stantchev, V.; Misra, S. Towards a social and context-aware mobile recommendation system for tourism. Pervasive Mob. Comput. 2017, 38, 505-515. [CrossRef]

13. Al-Shamri, M.Y.H. User profiling approaches for demographic recommender systems. Knowl. -Based Syst. 2016, 100, $175-187$. [CrossRef]

14. Safoury, L.; Salah, A. Exploiting User Demographic Attributes for Solving Cold-Start Problem in Recommender System. Lect. Notes Softw. Eng. 2013, 1, 303-307. [CrossRef]

15. Wang, Y.; Chan, S.C.-F.; Ngai, G.; Chan, C.F.S. Applicability of Demographic Recommender System to Tourist Attractions: A Case Study on Trip Advisor. In Proceedings of the 2012 IEEE/WIC/ ACM International Conferences on Web Intelligence and Intelligent Agent Technology, Macau, China, 4-7 December 2012; Institute of Electrical and Electronics Engineers (IEEE): Piscataway, NJ, USA, 2012; Volume 3, pp. 97-101.

16. Genç, R. The Impact of Augmented Reality (AR) Technology on Tourist Satisfaction. In Augmented Reality and Virtual Reality; Springer: Berlin/Heidelberg, Germany, 2017; pp. 109-116.

17. Khan, M.A.; Israr, S.; Almogren, A.S.; Din, I.U.; Almogren, A.; Rodrigues, J.J.P.C. Using augmented reality and deep learning to enhance Taxila Museum experience. J. Real-Time Image Process. 2021, 18, 321-332. [CrossRef]

18. Yue, Y.; Ding, J.; Kang, Y.; Wang, Y.; Wu, K.; Fei, T. A location-based social network system integrating mobile augmented reality and user generated content. In Proceedings of the 3rd ACM SIGSPATIAL International Workshop on Location-based Recommendations, Geosocial Networks and Geoadvertising-LocalRec '19, Chicago, IL, USA, 5 November 2019; Association for Computing Machinery (ACM): New York, NY, USA, 2019; p. 12.

19. Panou, C.; Ragia, L.; Dimelli, D.; Mania, K. An Architecture for Mobile Outdoors Augmented Reality for Cultural Heritage. ISPRS Int. J. Geo-Information 2018, 7, 463. [CrossRef]

20. Fenu, C.; Pittarello, F. Svevo tour: The design and the experimentation of an augmented reality application for engaging visitors of a literary museum. Int. J. Human-Computer Stud. 2018, 114, 20-35. [CrossRef]

21. Sadeghi-Niaraki, A.; Choi, S.-M. A Survey of Marker-Less Tracking and Registration Techniques for Health \& Environmental Applications to Augmented Reality and Ubiquitous Geospatial Information Systems. Sensors 2020, 20, 2997. [CrossRef]

22. De Pace, F.; Manuri, F.; Sanna, A. Augmented Reality in Industry 4.0. Am. J. Comput. Sci. Inf. Technol. 2018, 6, 17. [CrossRef] 
23. Leung, D.; Law, R.; van Hoof, H.; Buhalis, D. Social Media in Tourism and Hospitality: A Literature Review. J. Travel Tour. Mark. 2013, 30, 3-22. [CrossRef]

24. Vu, H.Q.; Li, G.; Law, R.; Zhang, Y. Tourist Activity Analysis by Leveraging Mobile Social Media Data. J. Travel Res. 2018, 57, 883-898. [CrossRef]

25. García-Palomares, J.C.; Gutiérrez, J.; Mínguez, C. Identification of tourist hot spots based on social networks: A comparative analysis of European metropolises using photo-sharing services and GIS. Appl. Geogr. 2015, 63, 408-417. [CrossRef]

26. Choi, H.; Han, G.C.; Kim, I.-J. Smart Booklet: Tour guide system with mobile augmented reality. In Proceedings of the 2014 IEEE International Conference on Consumer Electronics (ICCE), Las Vegas, NV, USA, 10-13 January 2014; Institute of Electrical and Electronics Engineers (IEEE): Piscataway, NJ, USA, 2014; pp. 353-354.

27. Narangajavana Kaosiri, Y.; Callarisa Fiol, L.J.; Moliner Tena, M.A.; Artola, R.M.R.; Sanchez Garcia, J. User-generated content sources in social media: A new approach to explore tourist satisfaction. J. Travel Res. 2019, 58, 253-265. [CrossRef]

28. Hernández, J.M.; Kirilenko, A.P.; Stepchenkova, S. Network approach to tourist segmentation via user generated content. Ann. Tour. Res. 2018, 73, 35-47. [CrossRef]

29. Li, J.; Xu, L.; Tang, L.; Wang, S.; Li, L. Big data in tourism research: A literature review. Tour. Manag. 2018, 68, 301-323. [CrossRef]

30. Barzegar, M.; Sadeghi-Niaraki, A.; Shakeri, M.; Choi, S.-M. A Context-Aware Route Finding Algorithm for Self-Driving Tourists Using Ontology. Electronics 2019, 8, 808. [CrossRef]

31. Zhao, W.X.; Li, S.; He, Y.; Wang, L.; Wen, J.-R.; Li, X. Exploring demographic information in social media for product recommendation. Knowl. Inf. Syst. 2016, 49, 61-89. [CrossRef]

32. Moscato, V.; Picariello, A.; Sperli, G. An emotional recommender system for music. In IEEE Intelligent Systems; IEEE: Piscataway, NJ, USA, 2020. [CrossRef]

33. Amato, F.; Moscato, V.; Picariello, A.; Sperli, G. KIRA: A System for Knowledge-Based Access to Multimedia Art Collections. In Proceedings of the 2017 IEEE 11th International Conference on Semantic Computing (ICSC), San Diego, CA, USA, 30 January-1 February 2017; Institute of Electrical and Electronics Engineers (IEEE): Piscataway, NJ, USA, 2017; pp. $338-343$.

34. Sadeghi-Niaraki, A.; Kim, K.; Varshosaz, M. Multi-criteria decision-based model for road network process. Int. J. Environ. Res. 2010, 4, 573-582.

35. Sadeghi-Niaraki, A. Industry 4.0 Development Multi-Criteria Assessment: An Integrated Fuzzy DEMATEL, ANP and VIKOR Methodology. IEEE Access 2020, 8, 23689-23704. [CrossRef]

36. Keršuliene, V.; Zavadskas, E.K.; Turskis, Z. Selection of rational dispute resolution method by applying new step-wise weight assessment ratio analysis (Swara). J. Bus. Econ. Manag. 2010, 11, 243-258. [CrossRef]

37. Zolfani, S.H.; Zavadskas, E.K.; Turskis, Z. Design of Products with Both International and Local Perspectives based on Yin-Yang Balance Theory and Swara Method. Econ. Res. Ekon. Istraživanja 2013, 26, 153-166. [CrossRef]

38. Zavadskas, E.K.; Stević, Ž.; Tanackov, I.; Prentkovskis, O. A Novel Multicriteria Approach-Rough Step-Wise Weight Assessment Ratio Analysis Method (R-SWARA) and Its Application in Logistics. Stud. Inform. Control. 2018, 27, 97-106. [CrossRef]

39. Zolfani, S.H.; Yazdani, M.; Zavadskas, E.K. An extended stepwise weight assessment ratio analysis (SWARA) method for improving criteria prioritization process. Soft Comput. 2018, 22, 7399-7405. [CrossRef]

40. Zolfani, S.H.; Chatterjee, P. Comparative Evaluation of Sustainable Design Based on Step-Wise Weight Assessment Ratio Analysis (SWARA) and Best Worst Method (BWM) Methods: A Perspective on Household Furnishing Materials. Symmetry 2019, 11, 74. [CrossRef]

41. Opricovic, S. Multicriteria optimization of civil engineering systems. Fac. Civ. Eng. Belgrade 1998, 2, 5-21.

42. Thrane, C.; Farstad, E. Domestic tourism expenditures: The non-linear effects of length of stay and travel party size. Tour. Manag. 2011, 32, 46-52. [CrossRef]

43. Pennington-Gray, L.; Fridgen, J.D.; Stynes, D. Cohort Segmentation: An Application to Tourism. Leis. Sci. 2003, 25, 341-361. [CrossRef]

44. Zhao, X.W.; Guo, Y.; He, Y.; Jiang, H.; Wu, Y.; Li, X. We know what you want to buy: A demographic-based system for product recommendation on microblogs. In Proceedings of the 20th ACM SIGKDD International Conference on Knowledge Discovery and Data Mining, New York, NY, USA, 24-27 August 2014; ACM: New York, NY, USA, 2014; pp. $1935-1944$.

45. Opricovic, S.; Tzeng, G.-H. Compromise solution by MCDM methods: A comparative analysis of VIKOR and TOPSIS. Eur. J. Oper. Res. 2004, 156, 445-455. [CrossRef]

46. Jahan, A.; Mustapha, F.; Ismail, Y.; Sapuan, S.; Bahraminasab, M. A comprehensive VIKOR method for material selection. Mater. Des. 2011, 32, 1215-1221. [CrossRef]

47. Yang, Y.-P.O.; Shieh, H.-M.; Leu, J.-D.; Tzeng, G.-H. A VIKOR-based multiple criteria decision method for improving information security risk. Int. J. Inf. Technol. Decis. Mak. 2009, 8, 267-287. [CrossRef]

48. Park, M.-H.; Hong, J.-H.; Cho, S.-B. Location-Based Recommendation System Using Bayesian User's Preference Model in Mobile Devices. In Proceedings of the International Conference on Ubiquitous Intelligence and Computing, Hong Kong, China, 11-13 July 2007; pp. 1130-1139.

49. Hedrick-Wong, Y.; Choong, D. Global Destination Cities Index by Mastercard. Available online: https://newsroommastercard. com/wp-content/uploads/2016/09 (accessed on 1 September 2018).

50. Myles, A.J.; Feudale, R.N.; Liu, Y.; Woody, N.A.; Brown, S.D. An introduction to decision tree modeling. J. Chemom. 2004, 18, 275-285. [CrossRef] 
51. Noble, W.S. What is a support vector machine? Nat. Biotechnol. 2006, 24, 1565-1567. [CrossRef] [PubMed]

52. da Silva, D.P.; da Costa, C.A.; Righi, R.d.; Costa, H.M. UbitourAR: A ubiquitous tourism model based on augmented reality. J. Appl. Comput. Res. 2015, 4, 23-34. [CrossRef]

53. Riaz, M. On Enhanced Interquartile Range Charting for Process Dispersion. Qual. Reliab. Eng. Int. 2015, 31. [CrossRef]

54. Barzegar, M.; Sadeghi-Niaraki, A.; Shakeri, M.; Choi, S.-M. An Improved Route-Finding Algorithm Using Ubiquitous OntologyBased Experiences Modeling. Complexity 2019, 2019, 1-15. [CrossRef] 